\title{
Heme Oxygenase-1 Upregulation: A Novel Approach in the Treatment of Cardiovascular Disease
}

Lars Bellner, ${ }^{1}$ Nachum B. Lebovics, ${ }_{1}$ Rochelle Rubinstein,, Yosef D. Buchen, ${ }^{1}$ Emilia Sinatra, Giuseppe Sinatra, Nader G. Abraham, ${ }^{1,2}$ John A. McClung, ${ }^{2}$ and Ellen A. Thompson ${ }^{3}$

\begin{abstract}
Significance: Heme oxygenase (HO) plays a pivotal role in both vascular and metabolic functions and is involved in many physiological and pathophysiological processes in vascular endothelial cells (ECs) and adipocytes.

Recent Advances: From the regulation of adipogenesis in adipose tissue to the adaptive response of vascular tissue in the ECs, HO plays a critical role in the capability of the vascular system to respond and adjust to insults in homeostasis. Recent studies show that HO-1 through regulation of adipocyte and adipose tissue functions ultimately aid not only in local but also in systemic maintenance of homeostasis.

Critical Issues: Recent advances have revealed the existence of a cross talk between vascular ECs and adipocytes in adipose tissue. In the pathological state of obesity, this cross talk contributes to the condition's adverse chronic effects, and we propose that specific targeting of the HO-1 gene can restore signaling pathways and improve both vascular and adipose functions.

Future Directions: A complete understanding of the role of HO-1 in regulation of cardiovascular homeostasis is important to comprehend the homeostatic regulation as well as in cardiovascular disease. Efforts are required to highlight the effects and the ability to target the HO-1 gene in models of obesity with an emphasis on the role of pericardial fat on cardiovascular health. Antioxid. Redox Signal. 32, 1045-1060.
\end{abstract}

Keywords: heme oxygenase, obesity, adipocytes, cardiovascular disease, oxidative stress

\section{Introduction}

$\mathbf{O}$ BESITY AND CARDIOMETABOLIC SYNDROME are on the rise worldwide, and its adverse health effects are insidious. Obesity is a major risk factor for vascular diseases, diabetes type 2 , and insulin resistance, as well as fatty liver $(2,8,11,43,50,87)$, while increasing inflammatory cytokines $(2,20,77)$. The association between obesity and heart failure is evident with a prevalence of $70 \%$ in individuals morbidly obese for 20 years and $90 \%$ in those morbidly obese for 30 years (10).

The consequences of obesity-mediated adipose tissue dysfunction may be extensive as fluctuations in adipose tissue-derived paracrine factors, including adipokines and cytokines, may affect the function of other organ systems, especially the cardiovascular system, and can lead to atherosclerosis and cardiovascular disease (CVD) $(2,37,134)$. Although obesity and metabolic syndrome can be treated with diet and lifestyle changes, patient compliance is low and long-term success is difficult to maintain for many of these patients. Thus, there is an increasing focus on developing potential new therapeutic strategies to decrease and even reverse the clinical complications of obesity and metabolic syndrome $(2,6,84,129)$.

One enzyme that has emerged as a key player in modulating metabolic disease is heme oxygenase (HO). In humans,

Departments of ${ }^{1}$ Pharmacology and ${ }^{2}$ Medicine, New York Medical College, Valhalla, New York.

${ }^{3}$ Department of Medicine, Marshall University, Joan C. Edwards School of Medicine, Huntington, West Virginia. 
$\mathrm{HO}$ exists as isozymes HO-1, the inducible form, and HO-2, the constitutive form. Both isozymes are alike in terms of mechanism, cofactor and substrate requirements, and in their susceptibility to activation or inhibition by synthetic metalloporphyrins, in which the central iron atom of heme has been replaced by other elements including tin, zinc, cobalt, and chromium $(2,3)$. HO is responsible for the degradation of heme (a pro-oxidant and also a strong inducer of HO-1), resulting in the formation of equimolar amounts of carbon monoxide (CO), iron, and biliverdin, which is then converted to bilirubin by biliverdin reductase $(1,2,7,64)$. Bilirubin and biliverdin have been found to be potent antioxidants, and induction of HO-1 reduces adiposity and oxidative stress, decreases excessive heme levels, and increases antioxidant enzymes, such as superoxide dismutase and catalase $(3,31,119,121,124)$. Bilirubin has also been shown to inhibit NADPH oxidase and protein kinase activity $(75,95$, 115). In addition, albumin-bound and free bilirubin inhibits oxidation of low-density lipoprotein (LDL), thereby preventing atherosclerosis $(44,95)$.

HO-1 is induced by a broad range of compounds and is considered the first line of defense against oxidative stress, provided that oxidative stress is a strong inducer of HO-1. Increased expression of $\mathrm{HO}-1$ enables cells to resist injury by heme and reactive oxygen species (ROS). Thus, induction of $\mathrm{HO}$ activity is central to the antioxidant defense and exerts cytoprotective effects in the cardiovascular system, contributing to decreased cardiac remodeling $(2,4,83)$. This effect is apparent in patients with Gilbert's syndrome, whose higher serum bilirubin is associated with decreased risk for coronary artery disease $(27,51,95)$.

Deletion of the human HO-1 gene results in organ damage in the liver, kidney, and vasculature system. This damage is caused by severe heme and iron deposition, which results in increased levels of ROS $(65,67,88)$. Similarly, mice deficient in HO-1 have decreased iron utilization, increased heme levels in the systemic circulation, and a defective stress defense system $(101,102)$. Interestingly, HO-1-knockout mice exhibit sex-dependent effects, and HO- 1 expression in adipose tissue has a greater protective role in females compared with males in preventing hyperglycemia and insulinemia (56).

\section{HO-1 Genetic Polymorphisms and Their Impact on CVD}

Genetic polymorphism of the HMOXI gene indicates a significance of HO-1 expression in the pathogenesis of pulmonary and CVDs $(2,138)$. It is believed that the length of (GT)n repeats affect the transcriptional activity of the HMOX1 gene. Association exists between longer (GT)n repeats in the HMOXI gene promoter and reduced HO-1 inducibility by ROS present in cigarette smoke, thus predisposing to the development of emphysema $(2,138)$. Diabetic patients with Gilbert's syndrome and elevated levels of bilirubin are partially protected from vascular complications compared with diabetic patients with normal bilirubin levels $(2,60)$.

In an Asian population, patients carrying longer $(\geq 32)$ (GT)n repeats and who were diagnosed with type 2 diabetes had elevated oxidative stress levels and an increased risk of the development of coronary artery disease and atherosclerosis (2, 26). Meanwhile, patients with significant obesity-associated risk factors for coronary artery disease (hyperlipidemia, smoking, and diabetes), but with shorter $(<27)(G T) n$ repeats had reduced disease risk $(2,63)$. One cohort study performed to evaluate $H M O X 1$ gene promoter polymorphisms and the risk for restenosis after percutaneous transluminal angioplasty found that patients with short $(<25$ GT) dinucleotide repeats in the HMOXI gene promoter on either allele had reduced risk of restenosis compared with patients with longer dinucleotide repeats $(2,38)$. These data indicate that shorter dinucleotide repeats and upregulation of HMOX1 gene expression may be protective after balloon angioplasty.

However, not all studies support a clinical significance of the genetic polymorphism in the HMOX1 gene; for example, in a study of 1807 patients with coronary artery disease undergoing coronary stenting, no correlation was found between $H M O X 1$ promoter polymorphism and ischemic events $(2,127)$. In support of this finding, no evidence of a beneficial effect of low (GT)n repeats on survival rate of graft or recipient in clinical renal transplantation was observed $(2,28)$.

A single nucleotide polymorphism in the HMOX1 promoter, T(-413)A, has been described that correlate with a reduced incidence of ischemic heart disease $(2,89)$. A study of 3104 patients with vascular disease observed a correlation between restenosis after percutaneous coronary intervention and an angiotensin II type I receptor (AGTRI) $116 \mathrm{~A} / \mathrm{C}$ polymorphism, but no association with $H M O X 1$ polymorphism was observed $(2,136)$. These studies provide evidence for and/or contradict the role of the HMOX1 gene in genetic polymorphism and cardiovascular health and risk of disease. In a recent study, the role of $H M O X 1$ genetic polymorphism in CVD was investigated.

The authors focused on the incidence of stroke, myocardial infarction (MI), and vascular disease in patients registered between 1995 and 2010. After investigating more than 800 patients (aged 45-84 years), an association between the $H M O X 1$ variable number tandem repeat polymorphism and CVD was observed and confined to subjects with a high number of GT repeats on both alleles of the HMOX1 gene, providing evidence of atherogenesis and decreased antioxidant defense in patients with high risk of vascular complications $(2,92)$. These studies point to an important role of $H M O X 1$ gene regulation in atherosclerotic disease processes.

\section{Upregulation of HO-1 Using Gene Targeting and Pharmacological Agents}

The protective role of HO-1 has led to a wealth of research investigating the effect of pharmacological induction of HO1 levels; these include the use of Cobalt protoporphyrin IX (CoPP), hemin, apolipoprotein A1 (APOA1) mimetic peptides L-4F or D-4F, epoxyeicosatrienoic acid (EET), and peroxisome proliferator-activated receptor alpha (PPAR $\alpha$ ). Nonspecific HO-1 induction in mice has been found to attenuate inflammatory markers, reduce kidney damage, ameliorate fatty liver disease and hypertension $(2,35,36,52,113$, $122)$, and also to increase adiponectin levels and insulin sensitivity $(68,86,94,96)$ [Table 1 ; reviewed in Abraham and Kappas (3) and Drummond et al. (33)].

\section{HO-1 upregulation via nonspecific global gene transfer}

As HO-1 gene therapy provides a more stable and prolonged vascular protection than pharmacological induction does, subsequent studies investigated the effect of $\mathrm{HO}-1$ 
Table 1. List of Heme Oxygenase-1 Inducers, Including Both Pharmacological and Genetic, As Well As General and Tissue Specific

\begin{tabular}{lc}
\hline General inducers & Tissue-specific inducers \\
\hline CoPP & $\begin{array}{c}\text { VECAD-HO-1 lentiviral } \\
\text { vector (endothelial cells) } \\
\text { ap2-HO-1 lentiviral vector } \\
\text { ApoA-1 mimetic peptides } \\
\text { L-4F/D-4F } \\
\text { Heme arginate }\end{array}$ \\
$\begin{array}{c}\text { Adiponectin-HO-1 lentiviral } \\
\text { vector (adipocytes) } \\
\text { Intrarenal medullary } \\
\text { interstitial catheter }\end{array}$ \\
EET & $\begin{array}{c}\text { TALH-HO-1 lentiviral vector } \\
\text { (kidney cells) }\end{array}$ \\
Statins & \\
Aspirin & \\
Free and complexed metals & \\
Prostaglandins & \\
Niacin & \\
Paclitaxel & \\
Rapamycin & \\
Telmisartan & \\
Turmeric & \\
\hline
\end{tabular}

aP2, adipocyte protein 2; CoPP, cobalt protoporphyrin IX; EET, epoxyeicosatrienoic acid; HO-1, heme oxygenase-1; TALH, thick ascending loop of Henle; VECAD, vascular endothelial cadherin.

overexpression at the early stage of adipocyte dysfunction following high-fat diet (HFD) intake in mice. Induction of $\mathrm{HO}-1$ gene expression is associated with an increased number of preadipocytes. Conversely, suppression of HO-1 results in increased number of large adipocytes and increased insulin resistance (23).

\section{Pharmacological induction of HO activity}

Obesity in general, abdominal obesity in particular, is associated with insulin resistance and the pathogenesis of type 2 diabetes mellitus and hypertension, contributes to high serum levels of LDL and triglycerides and low serum levels of high-density lipoprotein, and leads to the development of atherosclerosis and associated CVD (2, 40, 82, 128). HO-1mediated decreases of ROS and of LDL were reported in a number of models of diabetes $(2,21,22)$. Leptin-deficient mice or mice fed a HFD exhibit a metabolic syndrome-like phenotype, which includes an increase in LDL that is amenable to rescue by increased levels of HO-1 and adiponectin $(2,21)$. Chronic HO-1 induction increased oxygen consumption and lowered body weight in obese melanocortin-4 receptor-deficient mice with an improvement in vascular function $(2,30,55)$. Pharmacological inducers of HO-1 and their effects have been reviewed by Abraham et al. (2).

Human microvessel endothelial cells (ECs) were treated with angiotensin II (Ang II) in the presence and absence of CoPP, with or without the inhibitor of $\mathrm{HO}$ activity, stannous (or tin) mesoporphyrin IX (SnMP). Conditioned medium (CM) from the ECs was added to cultures of mesenchymal stem cell (MSC)-derived adipocytes. Adipocytes incubated with CM from Ang II-treated ECs showed a marked increase in adipogenesis, whereas adipocytes incubated with CM from Ang II-treated EC concomitantly treated with CoPP attenu- ated adipogenesis. In contrast, CM from ECs treated with Ang II together with SnMP increased MSC adipogenesis. These results demonstrate that $\mathrm{CoPP}$ induces $\mathrm{HO}-1$ and SnMP inhibits $\mathrm{HO}$ activity. It further shows that $\mathrm{HO}$ activity can prevent the negative effects of Ang II.

The APOA1 mimetic peptide L-4F, a putative antidiabetic drug, improves endothelial function likely through its antioxidant and anti-inflammatory properties. In obese mice, L-4F increases adiponectin levels, improves insulin sensitivity, and reduces visceral adiposity (131). L-4F treatment prevented myocardial and coronary functional abnormalities in $\mathrm{db} / \mathrm{db}$ mice. These effects were associated with increased levels of HO-1 resulting in increased levels of anti-inflammatory, anti-oxidative, and vasodilatory actions through a mechanism involving increased levels of adiponectin, pAMPK, and peNOS (131).

Pharmacological (e.g., L-4F/D-4F, CoPP, heme arginate) or gene-mediated induction of HO-1 (2, 21, 22, 77, 85, 94, 96, 114) correlates with increased plasma adiponectin levels, a concomitant increase in the number of healthy adipocytes, improved insulin sensitivity, a lowering of blood pressure, and a decrease in inflammatory adipokines (2, 22, 68, 74, 84$86,96)$. The effect of HO-1 induction on adipocyte morphology was confirmed in Zucker diabetic rats $(2,85)$ and ob/ob diabetic mice, where increased levels of HO-1 and $\mathrm{HO}$ activity prevented weight gain and reduced visceral and subcutaneous fat deposition. In addition to the abovementioned means of induction, HO-1 can also be induced by a wide range of drugs, and naturally occurring compounds and elements, including niacin, aspirin, statins, eicosanoids such as EET, certain prostaglandins, as well as free and complexed metals $(1,2)$.

Additionally, upregulation of HO-1 decreases adipogenesis in MSCs and increases adiponectin levels in culture media, effects reversed by the inhibition of HO activity (2, $77,94)$, thus confirming an $\mathrm{HO}-1$-adiponectin-EET regulatory module that can be manipulated to reduce the negative impact of obesity, diabetes, and metabolic syndrome. This offers a portal into the therapeutic benefits of HO-1 upregulation and increase in $\mathrm{HO}$ activity. Chronic induction of HO-1 lowers body weight via increased oxygen consumption, an effect that is independent of the melanocortin-4 system as chronic induction of HO-1 in obese melanocortin-4 receptor-deficient mice still results in the attenuation of obesity and type II diabetes $(2,30,55)$. The increased oxygen consumption following HO-1 induction is likely mediated through an elevation of endogenous $\mathrm{CO}$ levels as chronic treatment of obese mice with a CO-releasing molecule (CORM) also attenuates obesity and increases oxygen consumption $(2,54)$.

\section{Tissue-specific targeting of $\mathrm{HO}-1$ gene}

Targeting the HO-1 gene with gene therapy to specific tissues has been effective in producing a local upregulation of HO-1:

Vasculature. Specific upregulation of HO-1 at the endothelium is accomplished by targeting the endotheliumspecific promoter, vascular endothelial cadherin (VECAD), which has been used to selectively express genes in this tissue $(25,46,76)$. Targeting ECs with HO-1 using the VECAD 
promoter attenuated hyperglycemia-mediated cell injury and apoptosis (25), and cell injury and apoptosis caused by hyperglycemia (14). Oxidative stress as a result of hyperglycemia has an important role in the development and progression of diabetic vascular complications $(14,73)$. Augmentation of superoxide formation by Ang II results in the development of hypertension and endothelial and renal dysfunction; this is prevented by VECAD-HO-1 transduction. HO-1 transduction was also associated with elevation of adiponectin levels, activation of the $5^{\prime}$ adenosine monophosphate-activated protein kinase (AMPK)-endothelial nitric oxide synthase (eNOS) pathway, and improved endothelial function coincident with decreased levels of inflammatory cytokines and oxidative stress in animals. These results demonstrated a significant vascular and renal protective role for endothelial HO-1 in an Ang II animal model of hypertension (25). The scheme in Figure 1 depicts how induction of HO-1 improves vascular reactivity.

Kidney. Overexpression of HO-1 in cultured thick ascending loop of Henle (TALH) cells and in transgenic mice with TALH-targeted overexpression of HO-1 has demonstrated that HO-1 protects against Ang II-mediated increases in oxidative stress, attenuates the development of Ang IIdependent hypertension (104), and decreases the levels of the sodium-potassium 2 chloride (NKCC2) transporter (104, 124). HO-1 can also help prevent acute kidney injury. This is clear because patients with long (GT)n repeats in the HMOX1 gene promoter have 1.58-fold higher odds of developing acute kidney injury after cardiac surgery compared with individuals with the shorter (GT)n repeats (34).

Myeloid cells. Classically activated macrophages (M1) are proinflammatory, whereas alternatively activated macrophages (M2) have anti-inflammatory properties. Targeting HO-1 expression in myeloid cells has many benefits (142). Myeloid cell-specific upregulation of HO-1 favors M2 macrophage polarization and has protective effects against ischemia-reperfusion injury (IRI), which develops after a previously blocked artery is reperfused. IRI is characterized by local inflammation and an increase of ROS that is caused by the sudden reintroduction of oxygen into ischemic tissue. HO-1 is upregulated after liver IRI, and HO-1-knockout mice have increased IRI, suggesting that HO-1 has a protective effect (142). In studies of macrophage polarization, a myeloidspecific HO-1 gene was knocked out in mice causing full deletion of HO-1 in macrophages. Bone marrow-derived macrophages were then cultured. The HO-1-deficient macrophages were found to have increased messenger RNA (mRNA) of proinflammatory M1 markers (C-X-C motif chemokine ligand 10 [CXCL10], interleukin- $\beta$ [IL-1 $\beta]$, and monocyte chemoattractant protein 1 [MCP-1]) and decreased mRNA of anti-inflammatory M2 markers (Arg1 and CD163) compared with controls. The HO-1 knockouts also had decreased M2 markers after treatment with IL-4. This suggests that HO-1 is involved in macrophage polarization, and the deletion of HO-1 favors the M1 reprogramming (142).

Myocardium. Cardiovascular risk factors associated with myocardial dysfunction and oxidative stress is often observed in obesity. One study performed to determine alterations in enzymatic redox patterns in obese patients with myocardial dysfunction found increased levels of ROS and ROSproducing enzymes and reduced levels of antioxidant defense enzymes, including mitochondrial aldehyde dehydrogenase and HO-1 (47). Targeted deletion of HO-1 in cardiomyocytes exposed to ROS impairs mitochondrial quality control (125). IRI and low levels of HO-1 are associated with an increased risk of ventricular fibrillation (VF) (91), and an inverse relationship between HO-1 levels and VF has been demonstrated (17). Induction of HO-1 using recombinant adeno-associated virus reduced post-ischemic inflammation in pigs (53). Moreover, the post-ischemic infiltration of inflammatory cells, including leukocytes, neutrophils, and monocytes into HO-1deficient hearts, was significantly increased (53). The protective effects of HO-1 overexpression in the heart tissue are further evidenced by prolonged survival of cardiac allografts, and reduced mortality and preserved left ventricular (LV)

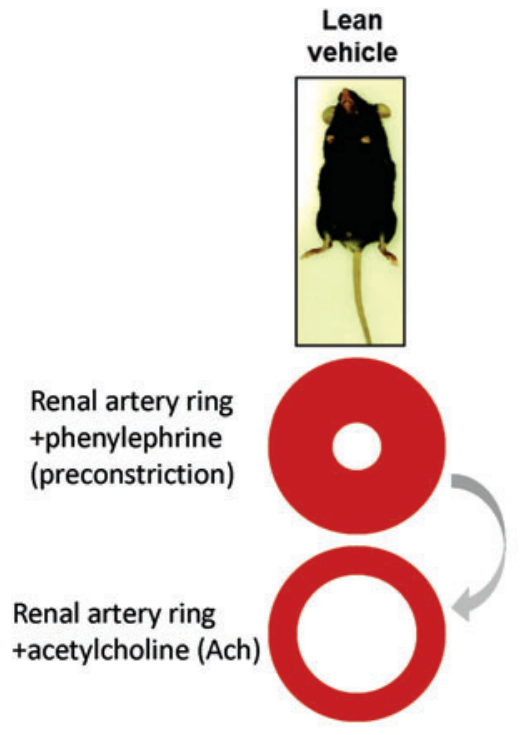

Normal response to Ach

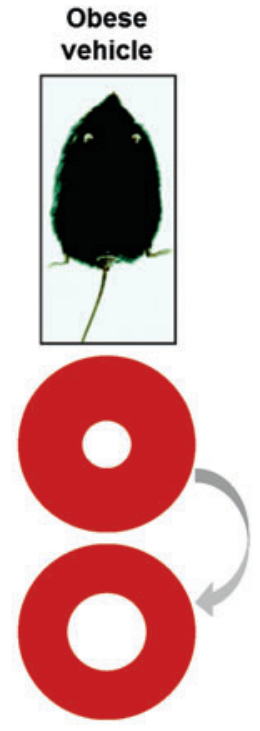

Impaired response to Ach

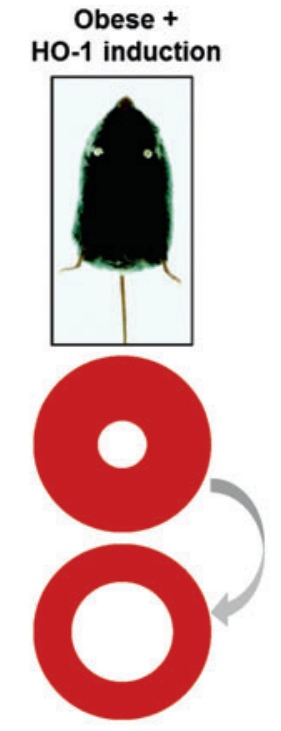

FIG. 1. Induction of HO1 improves vascular reactivity. Schematic depicting improved vascular reactivity in HFD-fed mice in which the HO-1 system has been induced $(5,25)$. Images of mice modified from the study of Li et al. (77), in which $\mathrm{HO}$ activity was induced by administration of CoPP. CoPP, cobalt protoporphyrin IX; HFD, high-fat diet; HO-1, heme oxygenase-1. Color images are available online. 
function after acute MI $(39,80)$. Figure 2 summarizes how HO-1 manipulation affects the heart function.

Adipose tissue. Using a lentiviral construct equipped with the adipocyte-targeting promoter for adipocyte protein 2 (aP2) to drive expression of HO-1 was associated with a several-fold increase in $\mathrm{HO}$ activity when compared with control vector (23). This effect was long lasting and attenuated adiposity and vascular dysfunction in mice fed a HFD. This offers a portal into therapeutic induction of HO-1.

\section{CYP2J2 Gene Targeting and the Role of EETs}

EETs and HO-1 are involved in a cellular mechanism that modulates mitochondrial function and ROS. EETs are arachidonic acid metabolites whose formation is catalyzed by the cytochrome p450 (CYP450) pathway (109). EETs are vasodilators and mediate many signaling cascades that reduce inflammation, apoptosis, and improve insulin sensitivity (109). Regarding adipocyte function specifically, EETs influence adipocyte phenotype in favor of small healthy adipocytes $(69,79,123,129,141)$. Downregulation of soluble epoxide hydrolase ( $\mathrm{sEH}$, an enzyme that converts EET to a less active class of lipids; dihydroxyeicosatrienoic acids) both in vitro and in vivo increases the number of small healthy adipocytes, increases the expression of thermogenic genes associated with beige fat, and increases adiponectin levels (79). Targeting ECs with CYP2J2 (cytochrome P450 family 2 subfamily $\mathrm{J}$ member 2, a member of the CYP450 family responsible for the EET production) using a tyrosine-protein kinase receptor (Tie2)-CYP2J2 transgenic mouse model decreases body weight, subcutaneous and visceral fat accumulation, blood glucose and inflammatory cytokines in mice fed a HFD while improving adiponectin levels and vascular function (5).

These effects of EET on adipocyte differentiation and phenotype are mediated by $\mathrm{HO}-1$ upregulation $(69,123)$. EET upregulation leads to increased levels of HO-1 $(5,69$,

FIG. 2. Scheme illustrating some of the effects observed in cardiac function after manipulation of $\mathrm{HO}-1$ levels. (A) Reversal of post-ischemic influx of inflammatory cells (53), (B) increased incidence of ischemia-reperfusion-induced ventricular fibrillation (17), (C) increased cardiac allograft survival (39), and (D) increased long-term survival and reduced myocardial fibrosis and scarring after acute myocardial infarction (80). AAV, adenoassociated virus; rAAV, recombinant adenoassociated virus; ZnPPIX, zinc protoporphyrin IX. Color images are available online.
123), and inhibition of HO activity using SnMP mitigates the positive effects of EET (123). Conversely, the activation of HO-1 gene expression increased EET levels (79), suggesting that HO-1 may contribute to the stimulation of EET production or the prevention of its degradation. Thus, EET and HO-1 appear to work in concert to achieve these beneficial effects.

The mechanism by which EET induces HO-1 has been explored. One mechanism that has been suggested is that EET leads to decreased expression of BTB domain and $\mathrm{CNC}$ homolog 1 (BACH-1), a transcriptional suppressor of HO-1 $(123,129)$. More recently, however, the effect of EET on HO-1 was reported to be mediated by peroxisome proliferatoractivated receptor gamma coactivator 1-alpha (PGC-1 $\alpha$ ). PGC $-1 \alpha$ is a protein initially described as an inducer of thermogenic genes and is now recognized as a major regulation of mitochondrial function and biogenesis (133). PGC- $1 \alpha$ works cooperatively with $\operatorname{PPAR} \delta$ to induce HO-1 transcription (9). Knockdown of PGC- $1 \alpha$ prevented EETmediated HO-1 induction (133). Thus, EET, HO-1, and PGC$1 \alpha$ constitute a cellular module that improves mitochondrial function and protects against inflammation triggered by ROS.

The relationship between HO-1, PGC- $1 \alpha$, and EET is schematized in Figure 2. Endothelial-specific targeting of the human CYP epoxygenase, CYP2J2, using the Tie2 promoter. Tie2-CYP2J2 transgenic mice, fed a HFD, had reduced body weight gain, blood glucose, insulin levels, and inflammatory markers (5). Tie2-CYP2J2 gene targeting restored HFDmediated decreases in vascular protein expression of $\mathrm{HO}-1$, Cyp2C44 (cytochrome P450, family 2, subfamily c, polypeptide 44), sEH, as well as phosphorylation levels of peNOS, pAKT, and pAMPK proteins, thus improving vascular function. These changes translated into decreased inflammation and oxidative stress within adipose tissue and decreased PPAR $\gamma, \mathrm{CCAAT} /$ enhancer binding protein alpha $(\mathrm{C} / \mathrm{EBP} \alpha)$, mesoderm-specific transcript (MEST), and aP2 expression and increased uncoupling protein (UCP) 1 and 2 expression, reflecting the effect of vascular EET

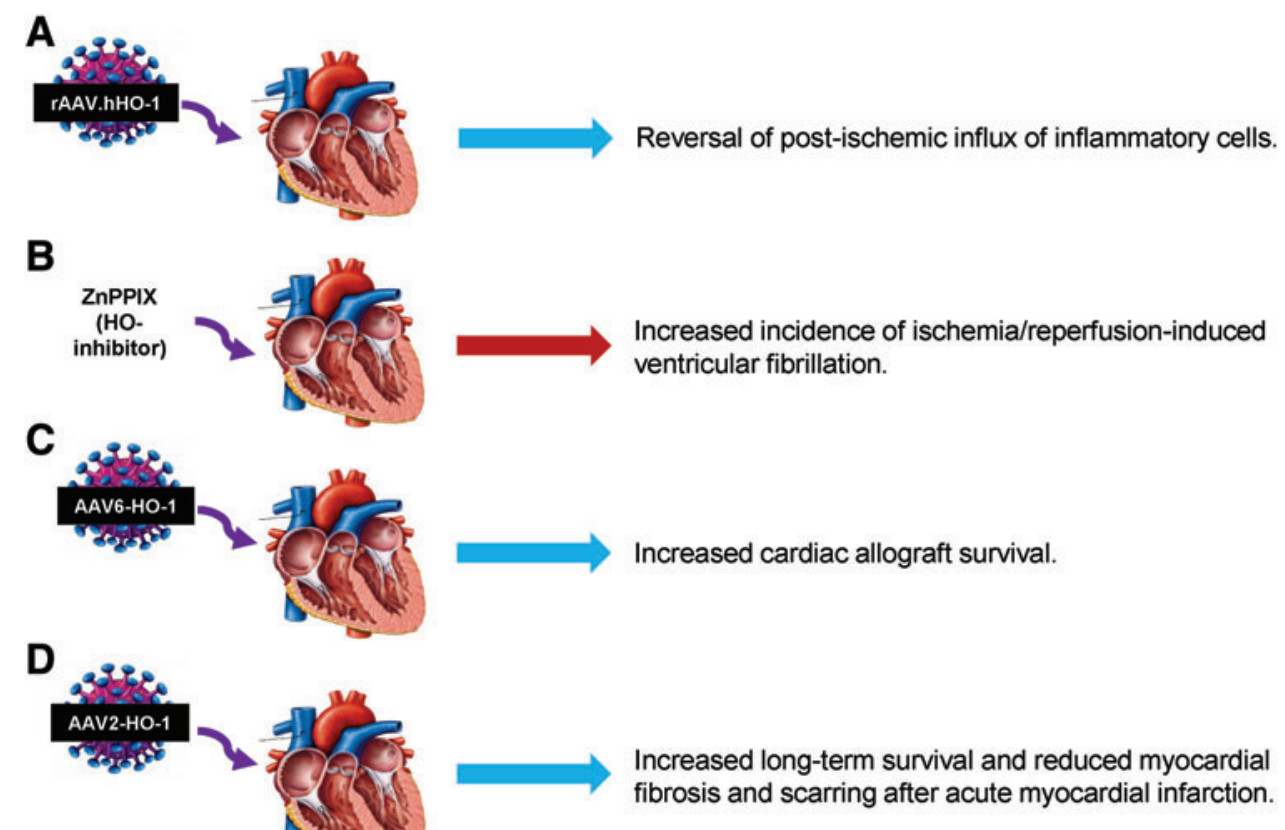


overproduction on adipogenesis. This study documented a direct link between endothelial-specific EET production and adipogenesis (5), further implicating the EET-HO-1 cross talk as an important cytoprotective mechanism in the amelioration of vascular and adipocyte dysfunction resulting from diet-induced obesity.

Furthermore, the role of HO-1 in improving adipocyte function in the current model is substantiated by previous work showing reduced adipogenesis via targeting HO-1 to adipocytes. UCP1 and UCP2 are expressed in adipose tissue that plays an important role in the control of energy expen- diture by uncoupling respiration from adenosine triphosphate (ATP) synthesis, thereby dissipates energy as heat and affects energy metabolism efficiency $(42,100,108)$. In agreement with these reports, results show that CYP2J2 transgenic (Tr) mice have increased adipose UCP1 and 2 levels compared with wild-type mice, and this could be one of the mechanisms involved in decreased adiposity in the CYP2J2 Tr mice. Taken together and summarized in Figure 3, the evidence supports a paracrine effect of endothelial EET production to improve both vascular and adipocyte functions through increased levels of HO-1. Thus, EET and HO-1 appear to form
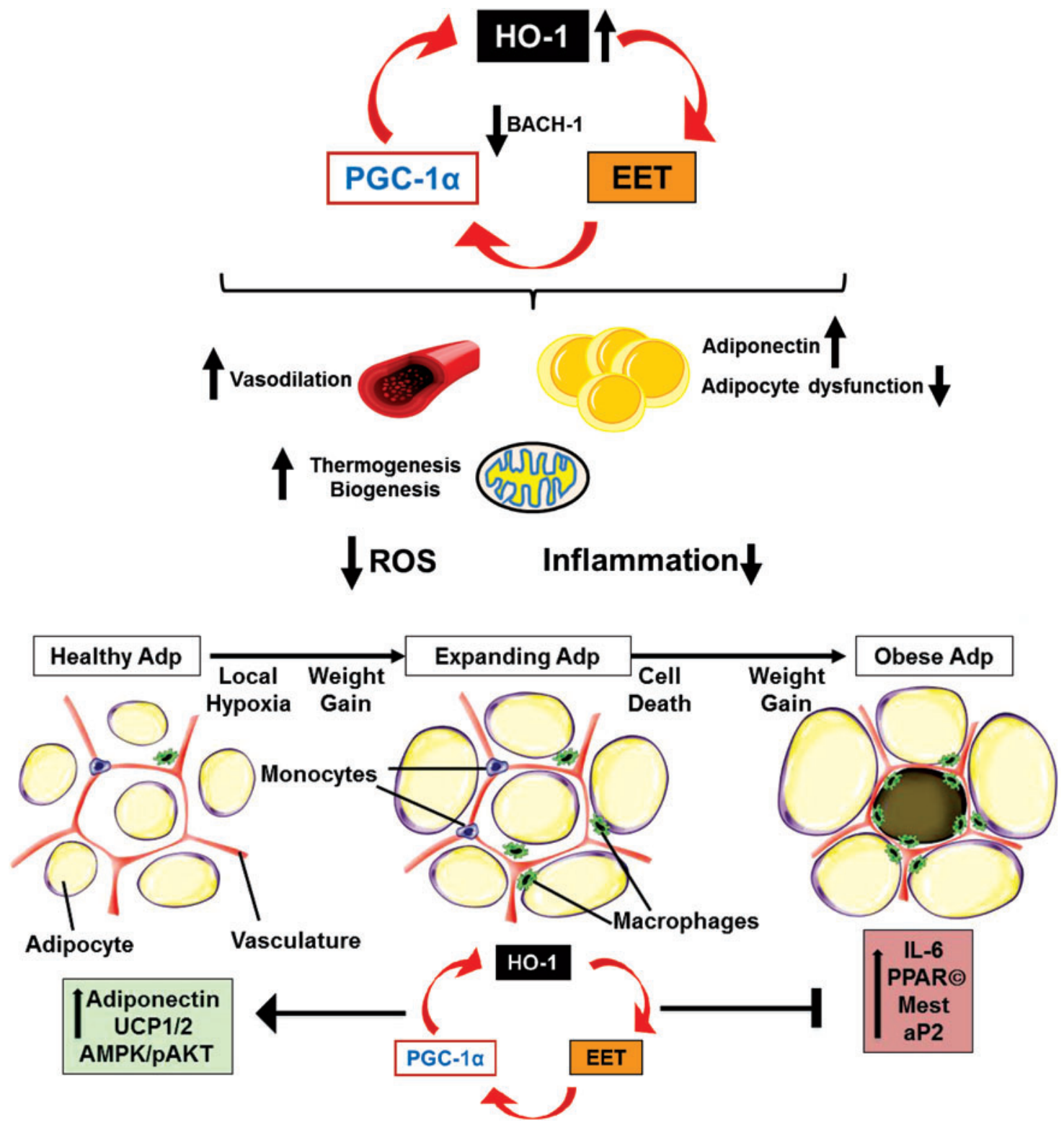

FIG. 3. Pharmacological or genetic induction of HO-1-EET-PGC-1 $\alpha$ axis. Schematic depicting pharmacological or genetic induction of HO-1-EET-HO- $1 \alpha$ axis $(121,133)$, as well as a decrease in HO-1 transcriptional suppressor, BACH-1 $(24,121,123,129)$. HO-1-PGC-1 $\alpha$-1EET feedback loop and some of the important effects observed systemically (reduced oxidative stress and inflammation), and in the vasculature (dilation) and adipose tissues (prevention or reversal of differentiation, and reduced inflammation). Also included are some of the effects observed on a subcellular level, that is, increased mitochondrial thermogenesis and biogenesis. Based on the HO-1-PGC-1 $\alpha$-EET axis action on adipocytes, the impaired exosomal secretion is likely increased with reversal of adipocyte dysfunction. BACH-1, BTB domain and CNC homolog 1; EET, epoxyeicosatrienoic acid; PGC-1 $\alpha$, peroxisome proliferator-activated receptor gamma coactivator 1-alpha. Color images are available online. 
a module that serves as a molecular "switch" to genetically reprogram the adipocyte phenotype to express lower levels of MEST and prevent hypoadiponectinemia.

One of the consequences of obesity-mediated adipocyte dysfunction is vascular dysfunction, which is a prelude to vascular disease and hypertension. With the growing prevalence of obesity and impaired glycemic control, the correlation between these conditions, and an elevated predisposition for the development of vascular disease, research emphasis is increasingly being targeted to the mechanistic basis and functional outcomes of these relationships. A direct link between endothelial-specific EET production and HO-1 induction to inhibit adipogenesis insults has been established (5). Thus, studies using CYP2J2 offer a portal to a role of HO-1-EET interplay in adipocyte-derived regulation of inflammation that is directly related to vascular dysfunction in obesity.

\section{Vascular Adipocyte Cross Talk in Obesity}

Upregulation of HO-1 in endothelial tissue also improves adipose tissue function. This is because endothelial tissue and adipose tissue are linked via a "cross talk" mechanism, where one affects the other. In experiments performed to elucidate this mechanism, EC-specific overexpression of HO-1 reduced adipocyte maturation resulting in smaller, insulin-sensitive adipocytes, and reduced intercellular adhesion molecule (ICAM), vascular cell adhesion molecule (VCAM), adipocyte-derived MCP-1, and tumor necrosis factor $\alpha(\mathrm{TNF} \alpha)$ levels (97). Moreover, administration of SnMP, an inhibitor of HO activity, reduced these effects, thus showing the dependence of HO-1 (97).

The size of the adipocyte is indicative of their function. Smaller adipocytes release larger amounts of the adipokine adiponectin, which is a significant contributor to the insulin sensitivity of these cells $(78,86,97,107,117,132)$. Larger "necrotic" adipocytes are insulin resistant and release markedly less adiponectin than their healthy counterparts $(15,97)$ (Fig. 3). Adipocyte size is also dependent on C/EBP$\alpha$ and PPAR $\gamma$, downstream activators of inflammatory cytokines, such as MCP-1, which stimulates the development of enlarged adipocytes that ultimately undergo inflammatory cell death, that is, necrosis $(49,57,62,110)$.

This highlights the crucial interaction between vascular function and adiposity. As a very active organ, adipose tissue is capable of secreting adipokines that affect the entire vascular system negatively or positively $(5,97)$. Particularly, adipose tissue surrounding the vasculature, the so-called perivascular adipose tissue, can interact with underlying vascular bed affecting its contractile tone $(97,106,126)$. In turn, the vascular endothelium can regulate expansion of surrounding adipose tissues. This adipose tissue-vascular bed homeostatic interaction is impaired in the case of morbid obesity, leading to the secretion of proinflammatory adipokines, as shown in models of obesity in mice $(16,97)$. The vascular endothelial growth factor (VEGF) led to key revelations about angiogenesis. One of these is that VEGF appears to be intimately involved with wound repair (61), which depends on vascular growth $(12,139)$.

For adipose tissue to expand, the vasculature needs to grow as well. This requires VEGF, which is readily provided by healthy ECs. In chronic obese mice, the appearance of large unhealthy, necrotic adipocytes was accompanied by in- creased levels of VCAM, TNF, ICAM, PPAR $\gamma$, and C/EBP along with reduced levels of adiponectin and wingless-type MMTV integration site family, member 10B (Wnt10b) (97). These negative effects were improved by upregulation of $\mathrm{HO}$ activity (mediated by CoPP treatment) (97). That these effects were dependent on HO-1 upregulation and $\mathrm{HO}$ activity was proven with the simultaneous treatment with SNMP, an inhibitor of $\mathrm{HO}$ activity, and that negated the observed positive effects (97). In addition, vascular relaxation in response to acetylcholine $(\mathrm{ACH})$ was improved by upregulation of HO-1 (97). Lentivirus-mediated genetic upregulation of HO-1 in mice was more effective in reducing the levels of inflammatory adipokines and had a greater effect on $\mathrm{ACH}$ mediated vascular relaxation than pharmacological induction of $\mathrm{HO}$ activity with $\mathrm{CoPP}(97)$. By growing adipocytes in $\mathrm{CM}$ derived from ECs transfected with either VECAD-HO-1 or a control vector, signaling originating from EC-influenced adipocyte activity including the production of inflammatory or anti-inflammatory adipokines (97).

Studies describing the use of VECAD-HO-1 gene transfer have examined the effect of HO-1 on the expression of nephroblastoma overexpressed (NOV/CCN3) and angiopoietin 1 (Angpt1), a potent growth factor that prevents adipogenesis and improves insulin resistance in vitro $(93,105)$ and also inhibits MSC differentiation into adipocytes $(70,97)$. NOV is a recently discovered adipocytokine involved in insulin resistance and many other pathophysiological processes, including cell adhesion, migration, proliferation, differentiation, and survival $(24,33,81,90)$.

Elevated NOV levels are associated with increased levels of a number of inflammatory cytokines that negatively impact insulin signaling, with a consequence of adipose tissue expansion and insulin resistance in patients with metabolic disorders $(90,117,120)$. In contrast, reduction in the level of NOV is associated with reduced adiposity, lowering of inflammatory cytokine levels, and enhanced insulin sensitivity in obese mice, effects associated with increased PGC- $1 \alpha$ expression in adipose tissue $(33,81,120)$. An EET agonist not only increases HO-1 levels but also downregulates NOV in adipose tissue of mice $(113,117)$. Targeting ECs with HO1 via gene transfer downregulated expression of NOV/CCN3 and resulted in a significant increase of Angpt 1 from EC with a concomitant increase in healthier lipid-sensitive adipocytes. The beneficial effect of Angpt1 was confirmed as adipogenesis was reduced in cells treated with Angpt1. Angpt1 also reduced the expression of NOV in adipocytes. These results show further evidence of the cross talk between the vascular tissue and the adipose tissue surrounding it and that targeting ECs with HO-1 via gene transfer has important therapeutic implications in the treatment of inflammation and adipocyte dysfunction due to obesity (97).

Direct targeting of EC by HO-1 through gene therapy is an effective way to reduce inflammatory adipocytokines, while also improving vascular function (Fig. 4). That HO-1 upregulation re-establishes the "cross talk" between the vascular system and the surrounding adipose tissue is evidenced by the observed reduction in adipose tissue expansion and improved vascular function. EC-specific HO-1 expression leads to a direct prolonged reduction of adipogenesis and offers future treatment directives for the management of obesity-associated chronic inflammation and vascular dysfunction (97). 


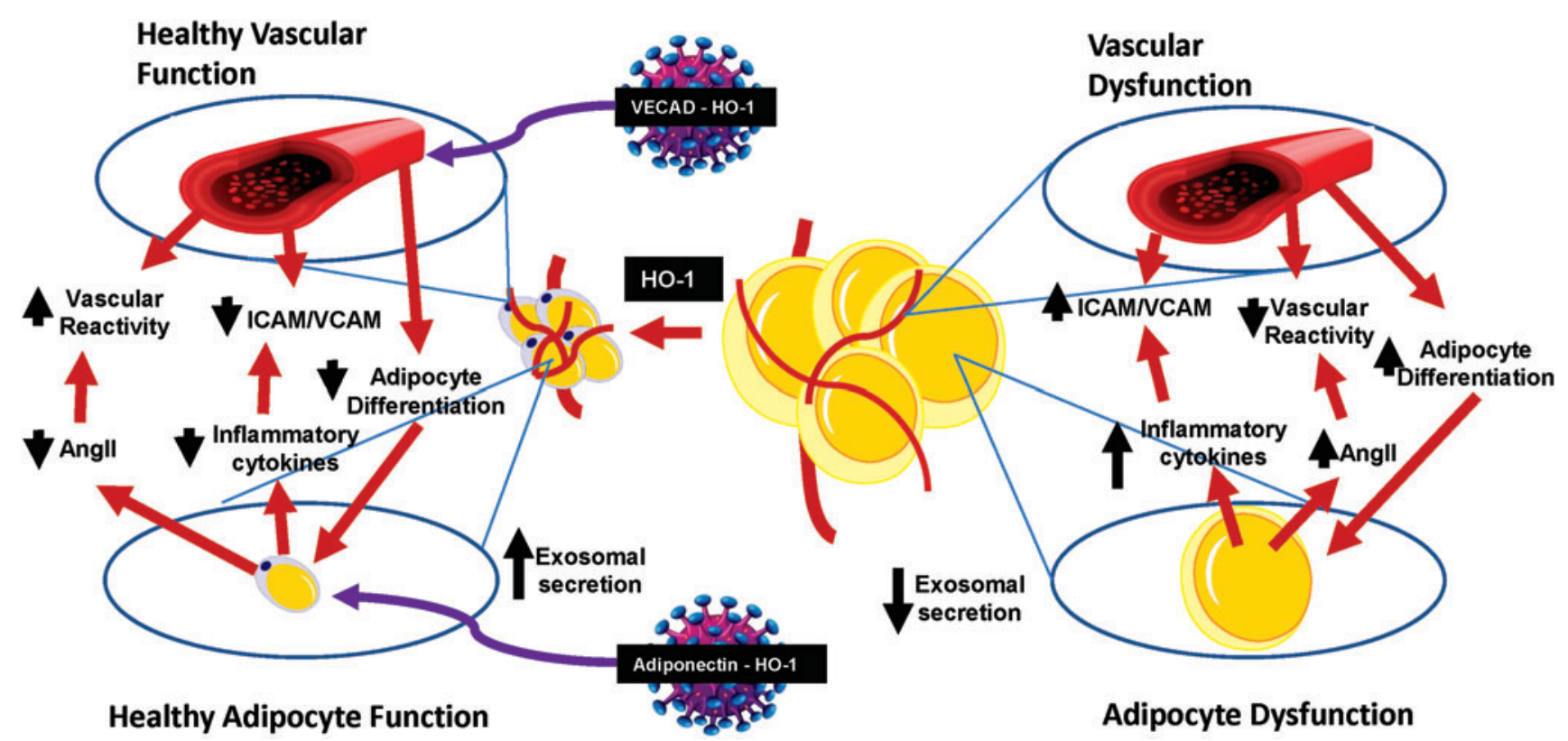

FIG. 4. Cross talk between adipocytes and vascular endothelial cells. Scheme illustrating the cross talk between vascular endothelial cells and adipocytes in both healthy and pathological states. Gene therapy targets that have been studied are indicated. Color images are available online.

\section{Cardioprotective and Vascular HO-1-PGC-1 $\alpha$ Signaling Attenuates Cardiovascular Risk in Humans As Well As in Obese Mice Model}

Leptin, adiponectin, and resistin are some of the signaling molecules secreted by adipose tissue (41). When homeostasis is disrupted, for instance, during inflammation, enlarged white adipocytes secrete several inflammatory cytokines $(98$, 117). In addition to the secretion of adipocytokines, adipocytes, as well as other cells in adipose tissues, secrete extracellular vesicles of endosomal origin used for cell-cell communications, including ECs and adipocytes in adipose tissues (29). Evidence shows that these vesicles, termed exosomes, reach the liver and influence glucose and lipid metabolism. The circulating levels of these exosomes correlate with adiponectin levels, and importantly, are inversely correlated with cellular ceramides causative agents of insulin resistance and CVD. Studies have also determined that metabolic disturbances, including obesity, change the effect of these secretory vesicles, based on their content in terms of cytokines, microRNAs (miRNAs), and so on. Exosomes isolated from adipose tissue macrophages of obese mice cause insulin resistance and glucose intolerance when administered to lean mice (140). Conversely, exosomes from adipose tissue macrophages from lean mice improved glucose metabolism when administered to obese mice (140). For review, see the study of Kita et al. (71).

Morbid obesity causes changes to the heart that include increased pericardial thickness in direct correlation with a high LV mass, decreased LF function $(41,111)$, and impaired fractional shortening (FS). Human adipose tissue locales are: beneath the skin (subcutaneous fat), in the larger bones (yellow bone marrow), surrounding internal organs (visceral fat), and in breast and muscular tissues. Surrounding the heart is visceral adipose tissue known as pericardial fat. Pericardial fat, together with the epicardial fat, is located between the outer wall of the myocardium and the visceral layer of pericardium $(58,59)$. When these adipose tissue depots become enlarged, they cause, directly or indirectly, significant cardiac remodeling, release ROS, and secrete inflammatory adipokines along with reduced levels of cytoprotective HO-1 and PGC- $1 \alpha(24,83,116,120)$. Please see the study of Iacobellis (58) for an excellent description of the anatomical differences between epicardial and pericardial fat. Increased epicardial fat deposition is associated with cardiomyopathy and cardiac remodeling $(45,48)$, and epicardial thickness may be a reliable marker for cardiovascular events, at least in females (41).

PGC- $1 \alpha$ plays a pivotal role in thermogenesis due to its regulation of $\operatorname{PPAR} \alpha$ in brown, mitochondria-rich adipose tissue (103), as well as maintains cellular energy metabolism and mitochondrial biogenesis and function (137). Somewhat increased levels of PGC- $1 \alpha$ in muscle cells of transgenic mice confer resistance to age-related obesity and diabetes, suggesting that PGC- $1 \alpha$ stimulates the secretion of factors that act globally (135). Deficiency of PGC- $1 \alpha$ specifically in adipocytes caused a decrease in mitochondrial biogenesis and led to impaired glucose metabolism and insulin resistance (72). Activation of PGC- $1 \alpha$ mediates HO- 1 expression that can, indirectly, further increase PGC- $1 \alpha$ levels (121). Similar to PGC- $1 \alpha$, changes in HO- 1 levels regulate mitochondrial biogenesis, function, as well as mitochondrial transport carriers $(31,99)$. In mice, cardiac tissue-specific overexpression of PGC- $1 \alpha$ activated mitochondrial biogenesis and proliferation $(13,112)$. Conversely, obese mice with adipose tissuespecific knockdown of PGC- $1 \alpha$ develop insulin resistance and have increased levels of circulating lipids (72).

There are several mechanisms that mediate HO-1s ability to reduce adiposity and vascular dysfunction in obese mouse models. One of these mechanisms is an increase in adiponectin expression resulting from products of heme degradation, namely bilirubin and $\mathrm{CO}$, which act to reduce vascular 
FIG. 5. Effect of HO-1 and PGC- $1 \alpha$ expression on left ventricular fractional shortening. Gene expression profiling revealing similar expression levels of (A) PGC- $1 \alpha$ and (B) HO-1 in epicardial and visceral fat depots of obese humans and mice. (C) Normalized left ventricular fractional shortening in obese+HO-1-induced mice. *Different from the corresponding control. Color images are available online.
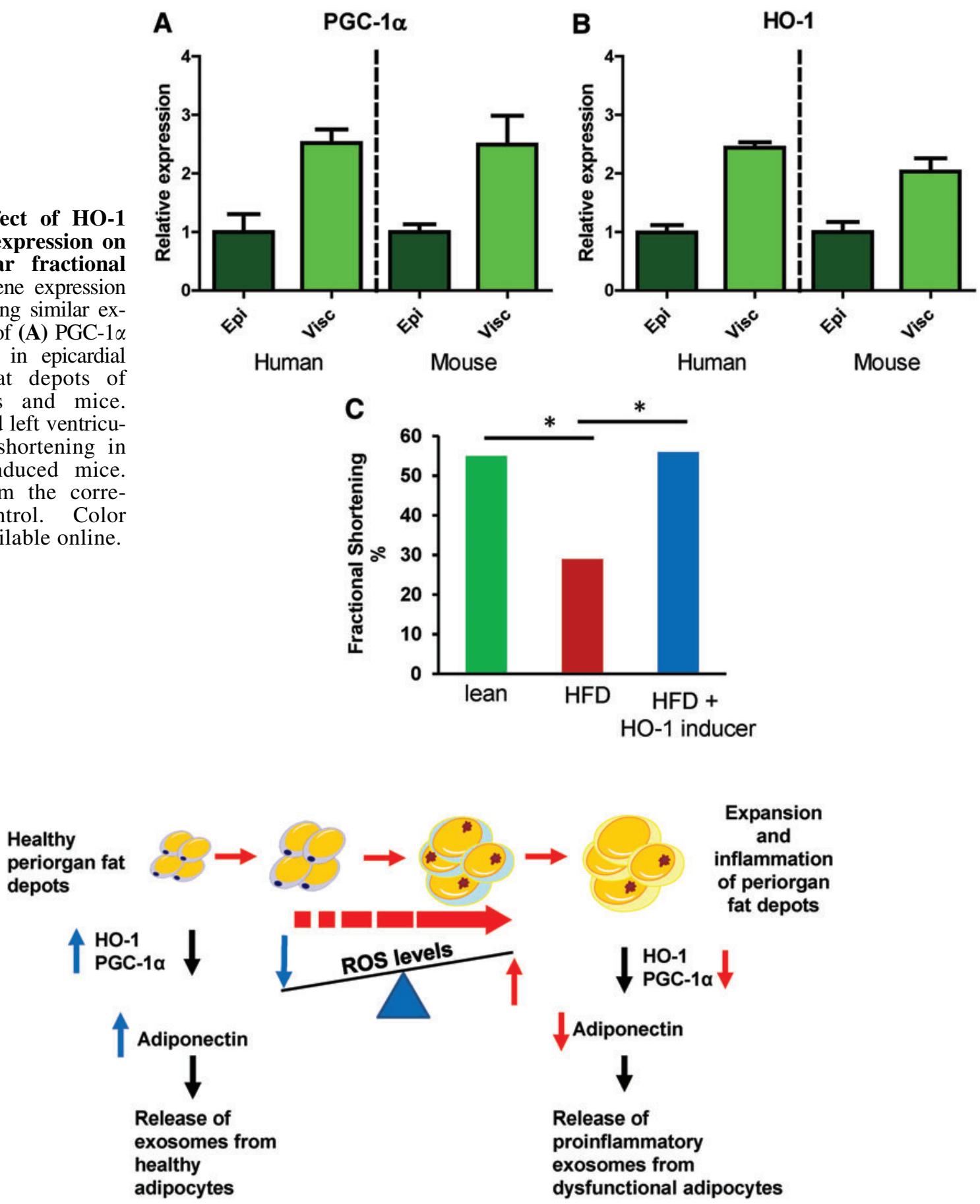

Maintenance of homeostasis

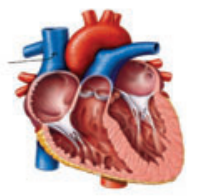

Disruption of homeostasis

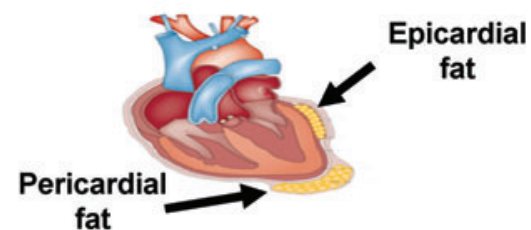

FIG. 6. Schematic depiction of how obesity and increased ROS levels give rise to inflamed dysfunctional visceral (including pericardial) adipose tissue, which altogether drives inflammation of the intraorgan (including epicardial) adipose tissues. There is a significant reduction in $\mathrm{HO}-1, \mathrm{PGC}-1 \alpha$, and adiponectin, in visceral and pericardial fat of obese mice, and obese humans with coronary disease when compared with same fat depots of lean mice and age- and gender-matched human controls, respectively. This imbalance causes a shift in the signaling molecule-content of adipocyte-secreted exosomes from supporting homeostasis to disruption thereof. This is accompanied by a reciprocal increase in levels of inflammatory cytokines in intraorgan fat depots, including epicardial fat, that causes organ dysfunction and disruption of homeostasis. ROS, reactive oxygen species. Color images are available online. 
dysfunction in models of hypertension $(19,55,66,77,86)$. Bilirubin also has anti-inflammatory effects on the heart, one of which is an increase in the bioavailability of nitric oxide (18). Bilirubin also decreases both markers of endoplasmic reticulum stress and inflammatory cytokine levels (32). However, HO-1 downregulation is associated with organ damage in both humans and mice resulting from a rise in ROS levels $(88,102)$.

Our group has previously demonstrated that HO-1 deficiency leads to an increase in white fat as opposed to brownlike fat via a reduction in PGC-1 $\alpha$, which in turn lowers MFN2 levels $(117,130)$. As noted earlier, PGC- $1 \alpha$ activation also mediates HO-1 expression, which have an indirect positive feedback effect on PGC- $1 \alpha$ expression by enhancing the activity of EET, which is located upstream of PGC-1 $\alpha$ in the signaling pathway. In this way, HO- 1 , PGC- $1 \alpha$, and EET influence each other in a positive feed-forward loop that significantly affects cardiovascular function (Figs. 3 and 6).

PGC- $1 \alpha$ inhibition is associated with a reduction in MFN2 and thermogenic genes such as PRDM16 with the result of an overall decrease in mitochondrial biogenesis. This decrease has multiple negative effects, including a reduction in energy expenditure, the conversion of brown fat to white fat, cardiac remodeling, and cardiomyopathy. Induction of the HO-1PGC1- $1 \alpha$ axis has also been found to reverse this process, and increased levels of HO- 1 and PGC- $1 \alpha$ are crucial to restoring LV function $(24,116,120)$.

The increase of FS in obese mice given an EET agonist has the simultaneous effects of inducing HO-1-PGC- $1 \alpha$ downstream signaling, markedly decreasing NOV protein expression in epicardial fat, and restoring ejection fraction and overall heart function. However, the reduction in HO-1 and PGC- $1 \alpha$ observed in obese mice not given the EET agonist was associated with increased NOV expression. This indicates that NOV is located downstream of either HO- 1 or PGC- $1 \alpha$. Downregulation of NOV is also associated with a reduction in the levels of other inflammatory adipocytokines $(24,116,120)$.

In this review, we present recent findings in a report (118) in which they compared expression profile of signaling pathways in adipose tissue isolated from diseased hearts with the expression profile in visceral fat. They compared their results with those obtained from same tissues of obese mice, in which the development of heart failure seems to result from changes in levels of inflammatory mediators and cytoprotective/antioxidant autacoids. Importantly, local adipose tissue seems to exert a more pronounced influence on the myocardium compared with other visceral adipose tissue.

By combining genome-wide and heatmap analyses of adipocyte gene expression, these researchers were able observe the expression levels of novel regulatory genes, which would help them identify influential epicardial fat adipokines. Their analysis yielded the same pattern in $\mathrm{HO}-1$ and PGC- $1 \alpha$ gene expression in both humans and mice-obese subjects exhibited a higher increase in visceral adipose tissue gene expression relative to epicardial fat tissue by a factor of $\sim 2$. This suggests the existence of conserved signaling pathway in these two species (Fig. 5A, B). Furthermore, an increase of HO-1-PGC-1 $\alpha$ was associated with an improvement in LV function in obese mice treated with an inducer of PGC- $1 \alpha$ HO-1 as evidenced by a normalization of the FS (Fig. 5C) and reduced inflammation and tissue remodeling (118). Figure 6 depicts a schematic of how obesity and increased ROS levels give rise to inflamed dysfunctional visceral (including pericardial) adipose tissue, which altogether drives inflammation of the intraorgan (including epicardial) adipose tissues and how these changes affect the PGC- $1 \alpha-\mathrm{HO}-1$ levels, and indicates how activation/enhancement of this pathway could lead to a return to cardiac homeostasis $(24,118,120)$.

To conclude, this review, and the discussed observations open a door toward further human studies aimed at investigating these pathways that have the potential of leading to the identification of novel targets for the treatment of obesityassociated CVDs.

\section{Acknowledgments}

All authors have read and agree with the manuscript as written. We thank Mrs. Jennifer Brown for her editorial assistance in preparing the manuscript.

\section{Funding Information}

This work was supported by National Institutes of Health grant [R 56-139561 to N.G.A.].

\section{References}

1. Abraham NG, Drummond GS, Lutton JD, and Kappas A. The biological significance and physiological role of heme oxygenase. Cell Physiol Biochem 6: 129-168, 1996.

2. Abraham NG, Junge JM, and Drummond GS. Translational significance of heme oxygenase in obesity and metabolic syndrome. Trends Pharmacol Sci 37: 17-36, 2016.

3. Abraham NG and Kappas A. Pharmacological and clinical aspects of heme oxygenase. Pharmacol Rev 60: 79-127, 2008.

4. Abraham NG, Rezzani R, Rodella L, Kruger A, Taller D, Li VG, Goodman AI, and Kappas A. Overexpression of human heme oxygenase-1 attenuates endothelial cell sloughing in experimental diabetes. Am J Physiol Heart Circ Physiol 287: H2468-H2477, 2004.

5. Abraham NG, Sodhi K, Silvis AM, Vanella L, Favero G, Rezzani R, Lee C, Zeldin DC, and Schwartzman ML. CYP2J2 targeting to endothelial cells attenuates adiposity and vascular dysfunction in mice fed a high-fat diet by reprogramming adipocyte phenotype. Hypertension 64: 1352-1361, 2014.

6. Abraham NG, Tsenovoy PL, McClung J, and Drummond GS. Heme oxygenase: a target gene for anti-diabetic and obesity. Curr Pharm Des 14: 412-421, 2008.

7. Ahmad Z, Salim M, and Maines MD. Human biliverdin reductase is a leucine zipper-like DNA-binding protein and functions in transcriptional activation of heme oxygenase-1 by oxidative stress. J Biol Chem 277: 92269232, 2002.

8. Akoumianakis I, Tarun A, and Antoniades C. Perivascular adipose tissue as a regulator of vascular disease pathogenesis: identifying novel therapeutic targets. $\mathrm{Br} J$ Pharmacol 174: 3411-3424, 2017.

9. Ali F, Ali NS, Bauer A, Boyle JJ, Hamdulay SS, Haskard DO, Randi AM, and Mason JC. PPARdelta and PGC1alpha act cooperatively to induce haem oxygenase-1 and enhance vascular endothelial cell resistance to stress. Cardiovasc Res 85: 701-710, 2010. 
10. Alpert MA, Terry BE, Mulekar M, Cohen MV, Massey CV, Fan TM, Panayiotou H, and Mukerji V. Cardiac morphology and left ventricular function in normotensive morbidly obese patients with and without congestive heart failure, and effect of weight loss. Am J Cardiol 80: 736-740, 1997.

11. Antonopoulos AS and Antoniades C. The role of epicardial adipose tissue in cardiac biology: classic concepts and emerging roles. J Physiol 595: 3907-3917, 2017.

12. Apte RS, Chen DS, and Ferrara N. VEGF in signaling and disease: beyond discovery and development. Cell 176: 1248-1264, 2019.

13. Arany Z, He H, Lin J, Hoyer K, Handschin C, Toka O, Ahmad F, Matsui T, Chin S, Wu PH, Rybkin II, Shelton JM, Manieri M, Cinti S, Schoen FJ, Bassel-Duby R, Rosenzweig A, Ingwall JS, and Spiegelman BM. Transcriptional coactivator PGC-1 alpha controls the energy state and contractile function of cardiac muscle. Cell Metab 1: 259-271, 2005.

14. Asija A, Peterson SJ, Stec DE, and Abraham NG. Targeting endothelial cells with heme oxygenase-1 gene using VE-cadherin promoter attenuates hyperglycemiamediated cell injury and apoptosis. Antioxid Redox Signal 9: 2065-2074, 2007.

15. Asterholm IW and Scherer PE. Enhanced metabolic flexibility associated with elevated adiponectin levels. Am J Pathol 176: 1364-1376, 2010.

16. Ayala-Lopez $\mathrm{N}$ and Watts SW. New actions of an old friend: perivascular adipose tissue's adrenergic mechanisms. Br J Pharmacol 174: 3454-3465, 2017.

17. Bak I, Papp G, Turoczi T, Varga E, Szendrei L, Vecsernyes M, Joo F, and Tosaki A. The role of heme oxygenase-related carbon monoxide and ventricular fibrillation in ischemic/reperfused hearts. Free Radic Biol Med 33: 639-648, 2002.

18. Bakrania B, Du Toit EF, Ashton KJ, Kiessling CJ, Wagner KH, Headrick JP, and Bulmer AC. Hyperbilirubinemia modulates myocardial function, aortic ejection, and ischemic stress resistance in the Gunn rat. Am J Physiol Heart Circ Physiol 307: H1142-H1149, 2014.

19. Braud L, Pini M, Muchova L, Manin S, Kitagishi H, Sawaki D, Czibik G, Ternacle J, Derumeaux G, Foresti R, and Motterlini R. Carbon monoxide-induced metabolic switch in adipocytes improves insulin resistance in obese mice. JCI Insight 3, 2018.

20. Briggs DB, Jones CM, Mashalidis EH, Nunez M, Hausrath AC, Wysocki VH, and Tsao TS. Disulfidedependent self-assembly of adiponectin octadecamers from trimers and presence of stable octadecameric adiponectin lacking disulfide bonds in vitro. Biochemistry 48 : 12345-12357, 2009.

21. Burgess A, Li M, Vanella L, Kim DH, Rezzani R, Rodella L, Sodhi K, Canestraro M, Martasek P, Peterson SJ, Kappas A, and Abraham NG. Adipocyte heme oxygenase-1 induction attenuates metabolic syndrome in both male and female obese mice. Hypertension 56: 1124-1130, 2010.

22. Cao J, Inoue K, Sodhi K, Puri N, Peterson SJ, Rezzani R, and Abraham NG. High-fat diet exacerbates renal dysfunction in SHR: reversal by induction of HO-1adiponectin axis. Obesity (Silver Spring) 20: 945-953, 2012.
23. Cao J, Peterson SJ, Sodhi K, Vanella L, Barbagallo I, Rodella LF, Schwartzman ML, Abraham NG, and Kappas A. Heme oxygenase gene targeting to adipocytes attenuates adiposity and vascular dysfunction in mice fed a highfat diet. Hypertension 60: 467-475, 2012.

24. Cao J, Singh SP, McClung J, Joseph G, Vanella L, Barbagallo I, Jiang H, Falck JR, Arad M, Shapiro JI, and Abraham NG. EET intervention on Wnt1, NOV and HO-1 signaling prevents obesity-induced cardiomyopathy in obese mice. Am J Physiol Heart Circ Physiol 313: H368H380, 2017.

25. Cao J, Sodhi K, Inoue K, Quilley J, Rezzani R, Rodella L, Vanella L, Germinario L, Stec DE, Abraham NG, and Kappas A. Lentiviral-human heme oxygenase targeting endothelium improved vascular function in angiotensin II animal model of hypertension. Hum Gene Ther 22: 271282, 2011.

26. Chen YH, Lin SJ, Lin MW, Tsai HL, Kuo SS, Chen JW, Charng MJ, Wu TC, Chen LC, Ding YA, Pan WH, Jou YS, and Chau LY. Microsatellite polymorphism in promoter of heme oxygenase-1 gene is associated with susceptibility to coronary artery disease in type 2 diabetic patients. Hum Genet 111: 1-8, 2002.

27. Clark JE, Foresti R, Sarathchandra P, Kaur H, Green CJ, and Motterlini R. Heme oxygenase-1-derived bilirubin ameliorates postischemic myocardial dysfunction. Am J Physiol Heart Circ Physiol 278: H643-H651, 2000.

28. Courtney AE, McNamee PT, Middleton D, Heggarty S, Patterson CC, and Maxwell AP. Association of functional heme oxygenase-1 gene promoter polymorphism with renal transplantation outcomes. Am J Transplant 7: 908913, 2007.

29. Crewe C, Joffin N, Rutkowski JM, Kim M, Zhang F, Towler DA, Gordillo R, and Scherer PE. An endothelialto-adipocyte extracellular vesicle axis governed by metabolic state. Cell 175: 695.e13-708.e13, 2018.

30. Csongradi E, Docarmo JM, Dubinion JH, Vera T, and Stec DE. Chronic HO-1 induction with cobalt protoporphyrin (CoPP) treatment increases oxygen consumption, activity, heat production and lowers body weight in obese melanocortin-4 receptor-deficient mice. Int J Obes (Lond) 36: 244-253, 2012.

31. Di Noia MA, Van DS, Palmieri F, Yang LM, Quan S, Goodman AI, and Abraham NG. Heme oxygenase-1 enhances renal mitochondrial transport carriers and cytochrome $\mathrm{C}$ oxidase activity in experimental diabetes. $J$ Biol Chem 281: 15687-15693, 2006.

32. Dong H, Huang H, Yun X, Kim DS, Yue Y, Wu H, Sutter A, Chavin KD, Otterbein LE, Adams DB, Kim YB, and Wang $H$. Bilirubin increases insulin sensitivity in leptin-receptor deficient and diet-induced obese mice through suppression of ER stress and chronic inflammation. Endocrinology 155: 818-828, 2014.

33. Drummond GS, Baum J, Greenberg M, Lewis D, and Abraham NG. HO-1 overexpression and underexpression: clinical implications. Arch Biochem Biophys 673: 108073, 2019.

34. Drummond HA, Mitchell ZL, Abraham NG, and Stec DE. Targeting heme oxygenase- 1 in cardiovascular and kidney disease. Antioxidants (Basel) 8, 2019.

35. Elmarakby AA, Faulkner J, Baban B, Saleh MA, and Sullivan JC. Induction of hemeoxygenase-1 reduces glomerular injury and apoptosis in diabetic spontaneously 
hypertensive rats. Am J Physiol Renal Physiol 302: F791F800, 2012.

36. Elmarakby AA, Faulkner J, Baban B, and Sullivan JC. Induction of hemeoxygenase-1 reduces renal oxidative stress and inflammation in diabetic spontaneously hypertensive rats. Int J Hypertens 2012: 957235, 2012.

37. Elmarakby AA and Imig JD. Obesity is the major contributor to vascular dysfunction and inflammation in high fat diet hypertensive rats. Clin Sci (Lond) 118: 291-301, 2010.

38. Endler G, Exner M, Schillinger M, Marculescu R, SunderPlassmann R, Raith M, Jordanova N, Wojta J, Mannhalter C, Wagner OF, and Huber K. A microsatellite polymorphism in the heme oxygenase- 1 gene promoter is associated with increased bilirubin and HDL levels but not with coronary artery disease. Thromb Haemost 91: 155-161, 2004.

39. Evans JM, Navarro S, Doki T, Stewart JM, Mitsuhashi N, and Kearns-Jonker M. Gene transfer of heme oxygenase-1 using an adeno-associated virus serotype 6 vector prolongs cardiac allograft survival. J Transplant 2012: 740653, 2012.

40. Fain JN, Madan AK, Hiler ML, Cheema P, and Bahouth SW. Comparison of the release of adipokines by adipose tissue, adipose tissue matrix, and adipocytes from visceral and subcutaneous abdominal adipose tissues of obese humans. Endocrinology 145: 2273-2282, 2004.

41. Fernandez Munoz MJ, Basurto Acevedo L, Cordova Perez N, Vazquez Martinez AL, Tepach Gutierrez N, Vega Garcia S, Rocha Cruz A, Diaz Martinez A, Saucedo Garcia R, Zarate Trevino A, Gonzalez Escudero EA, and Degollado Cordova JA. Epicardial adipose tissue is associated with visceral fat, metabolic syndrome, and insulin resistance in menopausal women. Rev Esp Cardiol (Engl Ed) 67: 436-441, 2014.

42. Flouris $\mathrm{AD}$, Dinas PC, Valente A, Andrade CMB, Kawashita NH, and Sakellariou P. Exercise-induced effects on UCP1 expression in classical brown adipose tissue: a systematic review. Horm Mol Biol Clin Investig 31, 2017.

43. Fontana L, Eagon JC, Trujillo ME, Scherer PE, and Klein S. Visceral fat adipokine secretion is associated with systemic inflammation in obese humans. Diabetes 56: 1010-1013, 2007.

44. Frei B, Stocker R, and Ames BN. Antioxidant defenses and lipid peroxidation in human blood plasma. Proc Natl Acad Sci U S A 85: 9748-9752, 1988.

45. Fuster JJ, Ouchi N, Gokce N, and Walsh K. Obesityinduced changes in adipose tissue microenvironment and their impact on cardiovascular disease. Circ Res 118: 1786-1807, 2016.

46. Gory S, Vernet M, Laurent M, Dejana E, Dalmon J, and Huber P. The vascular endothelial-cadherin promoter directs endothelial-specific expression in transgenic mice. Blood 93: 184-192, 1999.

47. Gramlich Y, Daiber A, Buschmann K, Oelze M, Vahl CF, Munzel T, and Hink U. Oxidative stress in cardiac tissue of patients undergoing coronary artery bypass graft surgery: the effects of overweight and obesity. Oxid Med Cell Longev 2018: 6598326, 2018.

48. Graner M, Pentikainen MO, Nyman K, Siren R, Lundbom J, Hakkarainen A, Lauerma K, Lundbom N, Nieminen MS, Petzold M, and Taskinen MR. Cardiac steatosis in patients with dilated cardiomyopathy. Heart 100: 11071112, 2014.
49. Hadrich F and Sayadi S. Apigetrin inhibits adipogenesis in 3T3-L1 cells by downregulating PPARgamma and CEBPalpha. Lipids Health Dis 17: 95, 2018.

50. Hall JE. The kidney, hypertension, and obesity. Hypertension 41: 625-633, 2003.

51. Hill-Kapturczak N, Chang SH, and Agarwal A. Heme oxygenase and the kidney. DNA Cell Biol 21: 307-321, 2002.

52. Hinds TD, Jr., Sodhi K, Meadows C, Fedorova L, Puri N, Kim DH, Peterson SJ, Shapiro J, Abraham NG, and Kappas A. Increased HO-1 levels ameliorate fatty liver development through a reduction of heme and recruitment of FGF21. Obesity (Silver Spring) 22: 705-712, 2014.

53. Hinkel R, Lange $\mathrm{P}$, Petersen $\mathrm{B}$, Gottlieb E, Ng JK, Finger S, Horstkotte J, Lee S, Thormann M, Knorr M, El-Aouni C, Boekstegers P, Reichart B, Wenzel P, Niemann $\mathrm{H}$, and Kupatt $\mathrm{C}$. Heme oxygenase-1 gene therapy provides cardioprotection via control of postischemic inflammation: an experimental study in a preclinical pig model. J Am Coll Cardiol 66: 154-165, 2015.

54. Hosick PA, AlAmodi AA, Storm MV, Gousset MU, Pruett BE, Gray W, III, Stout J, and Stec DE. Chronic carbon monoxide treatment attenuates development of obesity and remodels adipocytes in mice fed a high-fat diet. Int J Obes (Lond) 38: 132-139, 2014.

55. Hosick PA and Stec DE. Heme oxygenase, a novel target for the treatment of hypertension and obesity? Am J Physiol Regul Integr Comp Physiol 302: R207-R214, 2012.

56. Hosick PA, Weeks MF, Hankins MW, Moore KH, and Stec DE. Sex-dependent effects of HO-1 deletion from adipocytes in mice. Int J Mol Sci 18, 2017.

57. Hu HM, Tian Q, Baer M, Spooner CJ, Williams SC, Johnson PF, and Schwartz RC. The C/EBP bZIP domain can mediate lipopolysaccharide induction of the proinflammatory cytokines interleukin- 6 and monocyte chemoattractant protein-1. J Biol Chem 275: 16373-16381, 2000.

58. Iacobellis G. Epicardial and pericardial fat: close, but very different. Obesity (Silver Spring) 17: 625-627, 2009.

59. Iacobellis G, Corradi D, and Sharma AM. Epicardial adipose tissue: anatomic, biomolecular and clinical relationships with the heart. Nat Clin Pract Cardiovasc Med 2: 536-543, 2005.

60. Inoguchi T, Sasaki S, Kobayashi K, Takayanagi R, and Yamada T. Relationship between Gilbert syndrome and prevalence of vascular complications in patients with diabetes. JAMA 298: 1398-1400, 2007.

61. Jauhiainen S, Laakkonen JP, Ketola K, Toivanen PI, Nieminen T, Ninchoji T, Levonen AL, Kaikkonen MU, and Yla-Herttuala S. Axon guidance-related factor FLRT3 regulates VEGF-signaling and endothelial cell function. Front Physiol 10: 224, 2019.

62. Ji JD, Cheon H, Jun JB, Choi SJ, Kim YR, Lee YH, Kim TH, Chae IJ, Song GG, Yoo DH, Kim SY, and Sohn J. Effects of peroxisome proliferator-activated receptor-gamma (PPAR-gamma) on the expression of inflammatory cytokines and apoptosis induction in rheumatoid synovial fibroblasts and monocytes. J Autoimmun 17: 215-221, 2001.

63. Kaneda H, Ohno M, Taguchi J, Togo M, Hashimoto H, Ogasawara K, Aizawa T, Ishizaka N, and Nagai R. Heme 
oxygenase-1 gene promoter polymorphism is associated with coronary artery disease in Japanese patients with coronary risk factors. Arterioscler Thromb Vasc Biol 22: 1680-1685, 2002.

64. Kapitulnik $\mathbf{J}$ and Maines MD. Pleiotropic functions of biliverdin reductase: cellular signaling and generation of cytoprotective and cytotoxic bilirubin. Trends Pharmacol Sci 30: 129-137, 2009.

65. Kartikasari AE, Wagener FA, Yachie A, Wiegerinck ET, Kemna EH, and Swinkels DW. Hepcidin suppression and defective iron recycling account for dysregulation of iron homeostasis in heme oxygenase-1 deficiency. J Cell Mol Med 13: 3091-3102, 2009.

66. Kawamura K, Ishikawa K, Wada Y, Kimura S, Matsumoto $\mathrm{H}$, Kohro $\mathrm{T}$, Itabe $\mathrm{H}$, Kodama $\mathrm{T}$, and Maruyama Y. Bilirubin from heme oxygenase-1 attenuates vascular endothelial activation and dysfunction. Arterioscler Thromb Vasc Biol 25: 155-160, 2005.

67. Kawashima A, Oda Y, Yachie A, Koizumi S, and Nakanishi I. Heme oxygenase-1 deficiency: the first autopsy case. Hum Pathol 33: 125-130, 2002.

68. Kim DH, Burgess AP, Li M, Tsenovoy PL, Addabbo F, McClung JA, Puri N, and Abraham NG. Heme oxygenasemediated increases in adiponectin decrease fat content and inflammatory cytokines, tumor necrosis factor-alpha and interleukin-6 in Zucker rats and reduce adipogenesis in human mesenchymal stem cells. J Pharmacol Exp Ther 325: 833-840, 2008.

69. Kim DH, Vanella L, Inoue K, Burgess A, Gotlinger K, Manthati VL, Koduru SR, Zeldin DC, Falck JR, Schwartzman ML, and Abraham NG. Epoxyeicosatrienoic acid agonist regulates human mesenchymal stem cellderived adipocytes through activation of HO-1-pAKT signaling and a decrease in PPARgamma. Stem Cells Dev 19: 1863-1873, 2010.

70. Kim S, Lee JC, Cho ES, and Kwon J. COMP-Ang1 promotes chondrogenic and osteogenic differentiation of multipotent mesenchymal stem cells through the Ang1/ Tie2 signaling pathway. J Orthop Res 31: 1920-1928, 2013.

71. Kita S, Maeda N, and Shimomura I. Interorgan communication by exosomes, adipose tissue, and adiponectin in metabolic syndrome. J Clin Invest 129: 4041-4049, 2019.

72. Kleiner S, Mepani RJ, Laznik D, Ye L, Jurczak MJ, Jornayvaz FR, Estall JL, Chatterjee BD, Shulman GI, and Spiegelman BM. Development of insulin resistance in mice lacking PGC-1alpha in adipose tissues. Proc Natl Acad Sci U S A 109: 9635-9640, 2012.

73. Koya D, Hayashi K, Kitada M, Kashiwagi A, Kikkawa R, and Haneda M. Effects of antioxidants in diabetes-induced oxidative stress in the glomeruli of diabetic rats. J Am Soc Nephrol 14: S250-S253, 2003.

74. Kruger AL, Peterson SJ, Schwartzman ML, Fusco H, McClung JA, Weiss M, Shenouda S, Goodman AI, Goligorsky MS, Kappas A, and Abraham NG. Upregulation of heme oxygenase provides vascular protection in an animal model of diabetes through its antioxidant and antiapoptotic effects. J Pharmacol Exp Ther 319: 1144-1152, 2006.

75. Kwak JY, Takeshige K, Cheung BS, and Minakami S. Bilirubin inhibits the activation of superoxide-producing NADPH oxidase in a neutrophil cell-free system. Biochim Biophys Acta 1076: 369-373, 1991.
76. Lampugnani MG, Resnati M, Raiteri M, Pigott R, Pisacane A, Houen G, Ruco LP, and Dejana E. A novel endothelial-specific membrane protein is a marker of cellcell contacts. J Cell Biol 118: 1511-1522, 1992.

77. Li M, Kim DH, Tsenovoy PL, Peterson SJ, Rezzani R, Rodella LF, Aronow WS, Ikehara S, and Abraham NG. Treatment of obese diabetic mice with a heme oxygenase inducer reduces visceral and subcutaneous adiposity, increases adiponectin levels, and improves insulin sensitivity and glucose tolerance. Diabetes 57: 1526-1535, 2008.

78. Lin HV, Kim JY, Pocai A, Rossetti L, Shapiro L, Scherer $\mathrm{PE}$, and Accili D. Adiponectin resistance exacerbates insulin resistance in insulin receptor transgenic/knockout mice. Diabetes 56: 1969-1976, 2007.

79. Liu L, Puri N, Raffaele M, Schragenheim J, Singh SP, Bradbury JA, Bellner L, Vanella L, Zeldin DC, Cao J, and Abraham NG. Ablation of soluble epoxide hydrolase reprogram white fat to beige-like fat through an increase in mitochondrial integrity, $\mathrm{HO}-1$-adiponectin in vitro and in vivo. Prostaglandins Other Lipid Mediat 138: 1-8, 2018.

80. Liu X, Simpson JA, Brunt KR, Ward CA, Hall SR, Kinobe RT, Barrette V, Tse MY, Pang SC, Pachori AS, Dzau VJ, Ogunyankin KO, and Melo LG. Preemptive heme oxygenase-1 gene delivery reveals reduced mortality and preservation of left ventricular function $1 \mathrm{yr}$ after acute myocardial infarction. Am J Physiol Heart Circ Physiol 293: H48-H59, 2007.

81. Martinerie C, Garcia M, Do TT, Antoine B, Moldes M, Dorothee G, Kazazian C, Auclair M, Buyse M, Ledent T, Marchal PO, Fesatidou M, Beisseiche A, Koseki H, Hiraoka S, Chadjichristos CE, Blondeau B, Denis RG, Luquet S, and Feve B. NOV/CCN3: a new adipocytokine involved in obesity-associated insulin resistance. Diabetes 65: 2502-2515, 2016.

82. Mishra M and Ndisang JF. A critical and comprehensive insight on heme oxygenase and related products including carbon monoxide, bilirubin, biliverdin and ferritin in type1 and type-2 diabetes. Curr Pharm Des 20: 1370-1391, 2014.

83. Monu SR, Pesce P, Sodhi K, Boldrin M, Puri N, Fedorova L, Sacerdoti D, Peterson SJ, Abraham NG, and Kappas A. HO-1 induction improves the type-1 cardiorenal syndrome in mice with impaired angiotensin II-induced lymphocyte activation. Hypertension 62: 310-316, 2013.

84. Ndisang JF. Role of heme oxygenase in inflammation, insulin-signalling, diabetes and obesity. Mediators Inflamm 2010: 359732, 2010.

85. Ndisang JF, Jadhav A, and Mishra M. The heme oxygenase system suppresses perirenal visceral adiposity, abates renal inflammation and ameliorates diabetic nephropathy in Zucker diabetic fatty rats. PLoS One 9: e87936, 2014.

86. Nicolai A, Li M, Kim DH, Peterson SJ, Vanella L, Positano V, Gastaldelli A, Rezzani R, Rodella LF, Drummond G, Kusmic C, L'Abbate A, Kappas A, and Abraham NG. Heme oxygenase-1 induction remodels adipose tissue and improves insulin sensitivity in obesity-induced diabetic rats. Hypertension 53: 508-515, 2009.

87. Ogden CL, Carroll MD, Curtin LR, McDowell MA, Tabak CJ, and Flegal KM. Prevalence of overweight and obesity in the United States, 1999-2004. JAMA 295: 1549-1555, 2006. 
88. Ohta K, Yachie A, Fujimoto K, Kaneda H, Wada T, Toma T, Seno A, Kasahara Y, Yokoyama H, Seki H, and Koizumi S. Tubular injury as a cardinal pathologic feature in human heme oxygenase-1 deficiency. Am J Kidney Dis 35: 863-870, 2000.

89. Ono K, Goto Y, Takagi S, Baba S, Tago N, Nonogi H, and Iwai N. A promoter variant of the heme oxygenase-1 gene may reduce the incidence of ischemic heart disease in Japanese. Atherosclerosis 173: 315-319, 2004.

90. Pakradouni J, Le GW, Calmel C, Antoine B, Villard E, Frisdal E, Abifadel M, Tordjman J, Poitou C, BonnefontRousselot D, Bittar R, Bruckert E, Clement K, Feve B, Martinerie C, and Guerin M. Plasma NOV/CCN3 levels are closely associated with obesity in patients with metabolic disorders. PLoS One 8: e66788, 2013.

91. Pataki T, Bak I, Csonka C, Kovacs P, Varga E, Blasig IE, and Tosaki A. Regulation of ventricular fibrillation by heme oxygenase in ischemic/reperfused hearts. Antioxid Redox Signal 3: 125-134, 2001.

92. Pechlaner R, Willeit P, Summerer M, Santer P, Egger G, Kronenberg F, Demetz E, Weiss G, Tsimikas S, Witztum JL, Willeit K, Iglseder B, Paulweber B, Kedenko L, Haun M, Meisinger C, Gieger C, Muller-Nurasyid M, Peters A, Willeit J, and Kiechl S. Heme oxygenase-1 gene promoter microsatellite polymorphism is associated with progressive atherosclerosis and incident cardiovascular disease. Arterioscler Thromb Vasc Biol 35: 229236, 2015.

93. Pellegrinelli V, Rouault C, Veyrie N, Clement K, and Lacasa D. Endothelial cells from visceral adipose tissue disrupt adipocyte functions in a three-dimensional setting: partial rescue by angiopoietin-1. Diabetes 63: 535-549, 2014.

94. Peterson SJ, Drummond G, Kim DH, Li M, Kruger AL, Ikehara S, and Abraham NG. L-4F treatment reduces adiposity, increases adiponectin levels, and improves insulin sensitivity in obese mice. J Lipid Res 49: 16581669, 2008.

95. Peterson SJ and Frishman WH. Targeting heme oxygenase: therapeutic implications for diseases of the cardiovascular system. Cardiol Rev 17: 99-111, 2009.

96. Peterson SJ, Kim DH, Li M, Positano V, Vanella L, Rodella LF, Piccolomini F, Puri N, Gastaldelli A, Kusmic C, L'Abbate A, and Abraham NG. The L-4F mimetic peptide prevents insulin resistance through increased levels of HO-1, pAMPK, and pAKT in obese mice. J Lipid Res 50: 1293-1304, 2009.

97. Peterson SJ, Rubinstein R, Faroqui M, Raza A, Boumaza I, Zhang Y, Stec D, and Abraham NG. Positive effects of heme oxygenase upregulation on adiposity and vascular dysfunction: gene targeting vs. pharmacologic therapy. Int J Mol Sci 20, 2019.

98. Peterson SJ, Shapiro JI, Thompson E, Singh S, Liu L, Weingarten JA, O'Hanlon K, Bialczak A, Bhesania SR, and Abraham NG. Oxidized HDL, adipokines, and endothelial dysfunction: a potential biomarker profile for cardiovascular risk in women with obesity. Obesity (Silver Spring) 27: 87-93, 2019.

99. Piantadosi CA, Carraway MS, Babiker A, and Suliman HB. Heme oxygenase-1 regulates cardiac mitochondrial biogenesis via Nrf2-mediated transcriptional control of nuclear respiratory factor-1. Circ Res 103: 1232-1240, 2008.

100. Porter C. Quantification of UCP1 function in human brown adipose tissue. Adipocyte 6: 167-174, 2017.
101. Poss KD and Tonegawa $\mathrm{S}$. Heme oxygenase 1 is required for mammalian iron reutilization. Proc Natl Acad Sci U S A 94: 10919-10924, 1997.

102. Poss KD and Tonegawa S. Reduced stress defense in heme oxygenase 1-deficient cells. Proc Natl Acad Sci U S A 94: 10925-10930, 1997.

103. Puigserver $\mathrm{P}, \mathrm{Wu} \mathrm{Z}$, Park $\mathrm{CW}$, Graves R, Wright $\mathrm{M}$, and Spiegelman BM. A cold-inducible coactivator of nuclear receptors linked to adaptive thermogenesis. Cell 92: 829-839, 1998.

104. Quan S, Yang L, Shenouda S, Schwartzman ML, Nasjletti A, Goodman AI, and Abraham NG. Expression of human heme oxygenase- 1 in the thick ascending limb attenuates angiotensin II-mediated increase in oxidative injury. Kidney Int 65: 1628-1639, 2004.

105. Raffaele M, Bellner L, Singh SP, Favero G, Rezzani R, Rodella LF, Falck JR, Abraham NG, and Vanella L. Epoxyeicosatrienoic intervention improves NAFLD in leptin receptor deficient mice by an increase in PGC1alphaHO-1-PGC1alpha-mitochondrial signaling. Exp Cell Res 380: 180-187, 2019.

106. Ramirez JG, O'Malley EJ, and Ho WSV. Pro-contractile effects of perivascular fat in health and disease. $\mathrm{Br} \mathrm{J}$ Pharmacol 174: 3482-3495, 2017.

107. Rao JR, Keating DJ, Chen C, and Parkington HC. Adiponectin increases insulin content and cell proliferation in MIN6 cells via PPARgamma-dependent and PPARgamma-independent mechanisms. Diabetes Obes Metab 14: 983-989, 2012.

108. Rial E, Gonzalez-Barroso M, Fleury C, Iturrizaga S, Sanchis D, Jimenez-Jimenez J, Ricquier D, Goubern M, and Bouillaud F. Retinoids activate proton transport by the uncoupling proteins UCP1 and UCP2. EMBO $J 18$ : 5827-5833, 1999.

109. Romashko M, Schragenheim J, Abraham NG, and McClung JA. Epoxyeicosatrienoic acid as therapy for diabetic and ischemic cardiomyopathy. Trends Pharmacol Sci 37: 945-962, 2016.

110. Rosen ED, Hsu CH, Wang X, Sakai S, Freeman MW, Gonzalez FJ, and Spiegelman BM. C/EBPalpha induces adipogenesis through PPARgamma: a unified pathway. Genes Dev 16: 22-26, 2002.

111. Rosito GA, Massaro JM, Hoffmann U, Ruberg FL, Mahabadi AA, Vasan RS, O'Donnell CJ, and Fox CS. Pericardial fat, visceral abdominal fat, cardiovascular disease risk factors, and vascular calcification in a community-based sample: the Framingham Heart Study. Circulation 117: 605-613, 2008.

112. Rowe GC, Jiang A, and Arany Z. PGC-1 coactivators in cardiac development and disease. Circ Res 107: 825-838, 2010.

113. Sacerdoti D, Singh SP, Schragenheim J, Bellner L, Vanella L, Raffaele M, Meissner A, Grant I, Favero G, Rezzani R, Rodella LF, Bamshad D, Lebovics E, and Abraham NG. Development of NASH in obese mice is confounded by adipose tissue increase in inflammatory NOV and oxidative stress. Int J Hepatol 2018: 3484107, 2018.

114. Salley TN, Mishra M, Tiwari S, Jadhav A, and Ndisang JF. The heme oxygenase system rescues hepatic deterioration in the condition of obesity co-morbid with type-2 diabetes. PLoS One 8: e79270, 2013.

115. Sano K, Nakamura H, and Matsuo T. Mode of inhibitory action of bilirubin on protein kinase C. Pediatr Res 19: 587-590, 1985. 
116. Schragenheim J, Bellner L, Cao J, Singh SP, Bamshad D, McClung JA, Maayan O, Meissner A, Grant I, Stier CT, Jr., and Abraham NG. EET enhances renal function in obese mice resulting in restoration of $\mathrm{HO}-1-\mathrm{Mfn} 1 / 2$ signaling, and decrease in hypertension through inhibition of sodium chloride co-transporter. Prostaglandins Other Lipid Mediat 137: 30-39, 2018.

117. Singh S, Grant I, Meissner A, Kappas A, and Abraham N. Ablation of adipose-HO-1 expression increases white fat over beige fat through inhibition of mitochondrial fusion and of PGC1alpha in female mice. Horm Mol Biol Clin Investig 31, 2017.

118. Singh S, McClung J, Thompson E, Glick Y, Greenberg M, Acosta-Baez G, Edris B, Shapiro J, and Abraham NG. Cardioprotective heme oxygenase-1-PGC- $1 \alpha$ signaling in epicardial fat attenuates cardiovascular risk in humans as in obese mice. Obesity (Silver Spring) 27: 1634-1643, 2019.

119. Singh SP, Bellner L, Vanella L, Cao J, Falck JR, Kappas A, and Abraham NG. Downregulation of PGC1alpha prevents the beneficial effect of EET-heme oxygenase- 1 on mitochondrial integrity and associated metabolic function in obese mice. J Nutr Metab 2016: Article ID 9039754, 2016.

120. Singh SP, McClung JA, Bellner L, Cao J, Waldman M, Schragenheim J, Arad M, Hochhauser E, Falck JR, Weingarten JA, Peterson SJ, and Abraham NG. CYP-450 epoxygenase derived epoxyeicosatrienoic acid contribute to reversal of heart failure in obesity-induced diabetic cardiomyopathy via PGC-1 alpha activation. Cardiovasc Pharm Open Access 7: 2018.

121. Singh SP, Schragenheim J, Cao J, Falck JR, Abraham NG, and Bellner L. PGC-1 alpha regulates HO-1 expression, mitochondrial dynamics and biogenesis: role of epoxyeicosatrienoic acid. Prostaglandins Other Lipid Mediat 125: 8-18, 2016.

122. Sodhi K, Puri N, Favero G, Stevens S, Meadows C, Abraham NG, Rezzani R, Ansinelli H, Lebovics E, and Shapiro JI. Fructose mediated non-alcoholic fatty liver is attenuated by HO-1-SIRT1 module in murine hepatocytes and mice fed a high fructose diet. PLoS One 10: e0128648, 2015.

123. Sodhi K, Puri N, Inoue K, Falck JR, Schwartzman ML, and Abraham NG. EET agonist prevents adiposity and vascular dysfunction in rats fed a high fat diet via a decrease in Bach 1 and an increase in HO-1 levels. Prostaglandins Other Lipid Mediat 98: 133-142, 2012.

124. Stec DE, Drummond HA, Gousette MU, Storm MV, Abraham NG, and Csongradi E. Expression of heme oxygenase-1 in thick ascending loop of henle attenuates angiotensin II-dependent hypertension. J Am Soc Nephrol 23: 834-841, 2012.

125. Suliman HB, Keenan JE, and Piantadosi CA. Mitochondrial quality-control dysregulation in conditional $\mathrm{HO}-1^{-/-}$ mice. JCI Insight 2: e89676, 2017.

126. Szasz $\mathrm{T}$ and Webb RC. Perivascular adipose tissue: more than just structural support. Clin Sci (Lond) 122: $1-12,2012$.

127. Tiroch K, Koch W, von BN, Kastrati A, and Schomig A. Heme oxygenase-1 gene promoter polymorphism and restenosis following coronary stenting. Eur Heart $J$ 28: 968-973, 2007.

128. Tiwari S and Ndisang JF. The heme oxygenase system and type-1 diabetes. Curr Pharm Des 20: 1328-1337, 2014.
129. Vanella L, Kim DH, Sodhi K, Barbagallo I, Burgess AP, Falck JR, Schwartzman ML, and Abraham NG. Crosstalk between EET and HO-1 downregulates Bach1 and adipogenic marker expression in mesenchymal stem cell derived adipocytes. Prostaglandins Other Lipid Mediat 96: 54-62, 2011.

130. Vanella L, Sodhi K, Kim DH, Puri N, Maheshwari M, Hinds TD, Jr., Bellner L, Goldstein D, Peterson SJ, Shapiro JI, and Abraham NG. Increased heme-oxygenase 1 expression decreases adipocyte differentiation and lipid accumulation in mesenchymal stem cells via upregulation of the canonical Wnt signaling cascade. Stem Cell Res Ther 4: 28, 2013.

131. Vecoli C, Cao J, Neglia D, Inoue K, Sodhi K, Vanella L, Gabrielson KK, Bedja D, Paolocci N, L'Abbate A, and Abraham NG. Apolipoprotein A-I mimetic peptide L-4F prevents myocardial and coronary dysfunction in diabetic mice. J Cell Biochem 112: 2616-2626, 2011.

132. von Frankenberg AD, do Nascimento FV, Gatelli LE, Nedel BL, Garcia SP, de Oliveira CS, Saddi-Rosa P, Reis AF, Canani LH, and Gerchman F. Major components of metabolic syndrome and adiponectin levels: a crosssectional study. Diabetol Metab Syndr 6: 26, 2014.

133. Waldman M, Bellner L, Vanella L, Schragenheim J, Sodhi K, Singh SP, Lin D, Lakhkar A, Li J, Hochhauser E, Arad M, Darzynkiewicz Z, Kappas A, and Abraham NG. Epoxyeicosatrienoic acids regulate adipocyte differentiation of mouse $3 \mathrm{~T} 3$ cells, via PGC-1alpha activation, which is required for HO-1 expression and increased mitochondrial function. Stem Cells Dev 25: 1084-1094, 2016.

134. Wang ZV and Scherer PE. Adiponectin, cardiovascular function, and hypertension. Hypertension 51: 8-14, 2008.

135. Wenz T, Rossi SG, Rotundo RL, Spiegelman BM, and Moraes CT. Increased muscle PGC-1alpha expression protects from sarcopenia and metabolic disease during aging. Proc Natl Acad Sci U S A 106: 20405-20410, 2009.

136. Wijpkema JS, van Haelst PL, Monraats PS, Bruinenberg M, Zwinderman AH, Zijlstra F, van der SG, de Winter RJ, Doevendans PA, Waltenberger J, Jukema JW, and Tio RA. Restenosis after percutaneous coronary intervention is associated with the angiotensin-II type-1 receptor $1166 \mathrm{~A} / \mathrm{C}$ polymorphism but not with polymorphisms of angiotensin-converting enzyme, angiotensin-II receptor, angiotensinogen or heme oxygenase-1. Pharmacogenet Genomics 16: 331-337, 2006.

137. Wu Z, Puigserver P, Andersson U, Zhang C, Adelmant G, Mootha V, Troy A, Cinti S, Lowell B, Scarpulla RC, and Spiegelman BM. Mechanisms controlling mitochondrial biogenesis and respiration through the thermogenic coactivator PGC-1. Cell 98: 115-124, 1999.

138. Yamada N, Yamaya M, Okinaga S, Nakayama $K$, Sekizawa K, Shibahara S, and Sasaki H. Microsatellite polymorphism in the heme oxygenase- 1 gene promoter is associated with susceptibility to emphysema. Am J Hum Genet 66: 187-195, 2000.

139. Yang M, Chen Y, Wu Z, Zhang Y, Cai R, Ye L, Huang Y, Wang L, and He H. The impact of chronic intermittent hypoxia on the expression of intercellular cell adhesion molecule-1 and vascular endothelial growth factor in the ischemia-reperfusion rat model. Folia Neuropathol 56: 159-166, 2018.

140. Ying W, Riopel M, Bandyopadhyay G, Dong Y, Birmingham A, Seo JB, Ofrecio JM, Wollam J, Hernandez-Carretero A, Fu W, Li P, and Olefsky JM. 
Adipose tissue macrophage-derived exosomal miRNAs can modulate in vivo and in vitro insulin sensitivity. Cell 171: 372.e12-384.e12, 2017.

141. Zha W, Edin ML, Vendrov KC, Schuck RN, Lih FB, Jat JL, Bradbury JA, Degraff LM, Hua K, Tomer KB, Falck JR, Zeldin DC, and Lee CR. Functional characterization of cytochrome P450-derived epoxyeicosatrienoic acids in adipogenesis and obesity. J Lipid Res 55: 21242136, 2014.

142. Zhang M, Nakamura K, Kageyama S, Lawal AO, Gong KW, Bhetraratana M, Fujii T, Sulaiman D, Hirao H, Bolisetty S, Kupiec-Weglinski JW, and Araujo JA. Myeloid HO-1 modulates macrophage polarization and protects against ischemia-reperfusion injury. JCI Insight 3: pii:120596, 2018.

Address correspondence to:

Dr. Lars Bellner

Department of Pharmacology New York Medical College Valhalla, NY 10595

E-mail: lars_bellner@nymc.edu

Dr. Nader G. Abraham

Department of Pharmacology New York Medical College Valhalla, NY 10595

E-mail: nader_abraham@nymc.edu

Date of first submission to ARS Central, December 5, 2019; date of acceptance, December 19, 2019.

\section{Abbreviations Used}

$\mathrm{ACH}=$ acetylcholine

$\mathrm{AKT}=\mathrm{AKT}$ serine/threonine kinase 1

Ang II $=$ angiotensin II

Angpt $1=$ angiopoietin 1

$\mathrm{aP} 2=$ adipocyte protein 2

APOA $1=$ apolipoprotein A1
$\mathrm{C} / \mathrm{EBP} \alpha=\mathrm{CCAAT} / \mathrm{enhancer}$ binding protein alpha

$\mathrm{CM}=$ conditioned medium

$\mathrm{CO}=$ carbon monoxide

$\mathrm{CoPP}=$ cobalt protoporphyrin IX

$\mathrm{CVD}=$ cardiovascular disease

CYP2J2 = cytochrome P450 family 2 subfamily $\mathbf{J}$ member 2

CYP450 = cytochrome $\mathrm{p} 450$

$\mathrm{ECs}=$ endothelial cells

EET $=$ epoxyeicosatrienoic acid

$\mathrm{FS}=$ fractional shortening

$\mathrm{HFD}=$ high-fat diet

$\mathrm{HO}=$ heme oxygenase

ICAM $=$ intercellular adhesion molecule

$\mathrm{IL}=$ interleukin

IRI $=$ ischemia-reperfusion injury

$\mathrm{LDL}=$ low-density lipoprotein

$\mathrm{LV}=$ left ventricular

M1 = classically activated macrophages

M2 = alternatively activated macrophages

MCP-1 = monocyte chemoattractant protein 1

MEST $=$ mesoderm-specific transcript

$\mathrm{MI}=$ myocardial infarction

mRNA $=$ messenger RNA

$\mathrm{MSC}=$ mesenchymal stem cell

$\mathrm{NOV} / \mathrm{CCN} 3=$ nephroblastoma overexpressed

PGC- $1 \alpha=$ peroxisome proliferator-activated receptor gamma coactivator 1 -alpha

$\mathrm{PPAR}=$ peroxisome proliferator-activated receptor

ROS $=$ reactive oxygen species

$\mathrm{sEH}=$ soluble epoxide hydrolase

SnMP $=$ stannous (or tin) mesoporphyrin IX

$\mathrm{TALH}=$ thick ascending loop of Henle

Tie $=$ tyrosine-protein kinase receptor

$\mathrm{TNF}=$ tumor necrosis factor

$\operatorname{Tr}=$ transgenic

$\mathrm{UCP}=$ uncoupling protein

$\mathrm{VCAM}=$ vascular cell adhesion molecule

VECAD $=$ vascular endothelial cadherin

$\mathrm{VEGF}=$ vascular endothelial growth factor $\mathrm{VF}=$ ventricular fibrillation 